TOWARD EFFECTIVE AND EFFICIENT TREATMENT ADHERENCE MONITORING: DEVELOPMENT OF THE COGNITIVE BEHAVIORAL THERAPY

ADHERENCE MEASURE

\begin{tabular}{c} 
A Dissertation \\
presented to \\
the Faculty of the Graduate School \\
at the University of Missouri-Columbia \\
In Partial Fulfillment \\
of the Requirements for the Degree \\
Doctor of Philosophy \\
\hline Dr. Kristin M. Hawley, Dissertation Supervisor \\
bVy
\end{tabular}

JULY 2021 
The undersigned, appointed by the dean of the Graduate School, have examined the dissertation entitled

TOWARD EFFECTIVE AND EFFICIENT TREATMENT ADHERENCE

MONITORING: DEVELOPMENT OF THE COGNITIVE BEHAVIORAL THERAPY

ADHERENCE

presented by Evelyn Cho,

a candidate for the degree of Doctor of Philosophy,

and hereby certify that, in their opinion, it is worthy of acceptance.

Professor Kristin M. Hawley

Professor Debora J. Bell

Professor Edgar C. Merkle

Professor Keith C. Herman 


\section{ACKNOWLEDGEMENTS}

I thank Dr. Kristin M. Hawley for her invaluable mentorship, guidance, and support without which this project would not have been possible. I would also like to thank Drs. Debora J. Bell, Edgar C. Merkle, and Keith C. Herman for their time and contributions that served to strengthen this project. Finally, this project was funded by NIMH Grant \# R21 MH090460 awarded to Dr. Kristin M. Hawley. 


\section{TABLE OF CONTENTS}

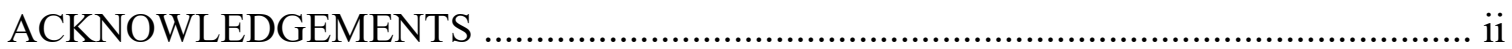

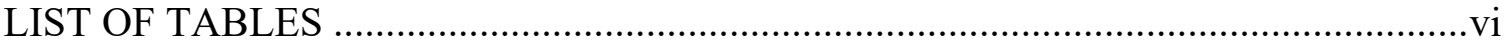

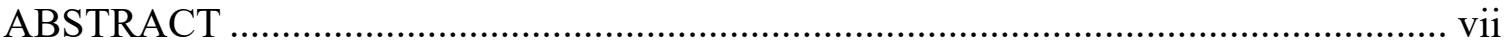

\section{Chapter}

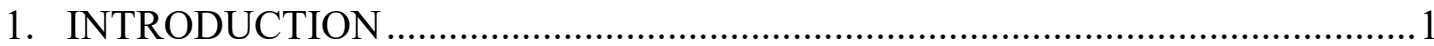

Current Adherence Monitoring Methods ................................................................

Participant-Rated Adherence Measures ..........................................................5

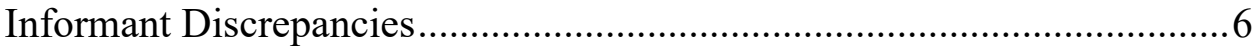

Current Participant-Rated Adherence Measures .................................... 8

A Transdiagnostic, Components Approach to Adherence Measurement................9

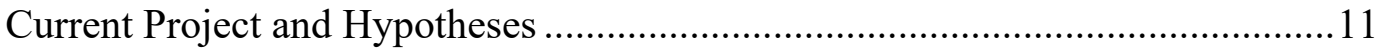

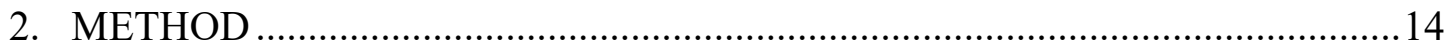

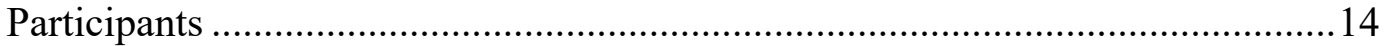

Study Design and Procedures ..................................................................... 14

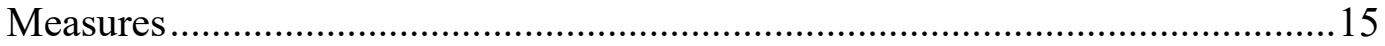

Data Analytic Plan.............................................................................................24

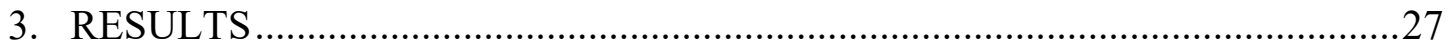

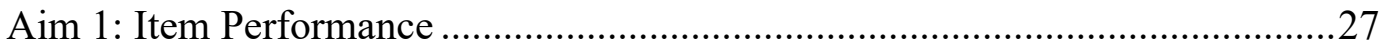


Aim 2: Participant-Coder Consistency

Aim 3: Convergent and Discriminant Validity ............................................28

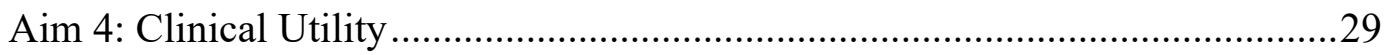

Aim 5: Examine Performance of the End-of-Treatment CBTAM Scores ............30

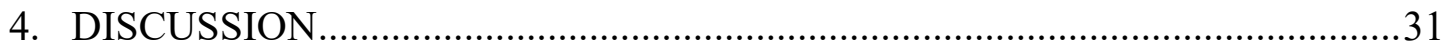

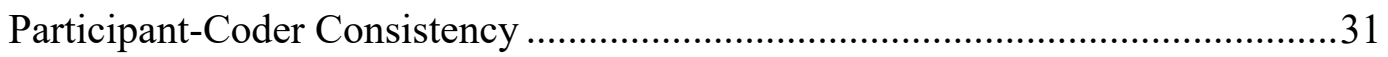

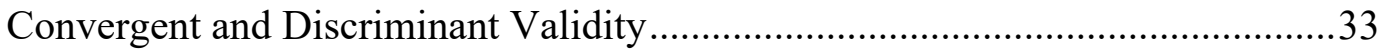

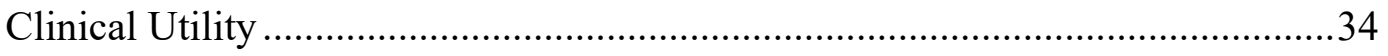

Psychometric Properties of the End-of-Treatment CBTAMs .............................37

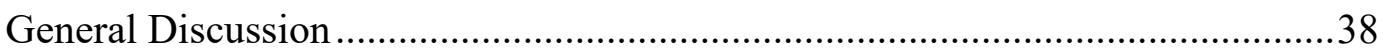

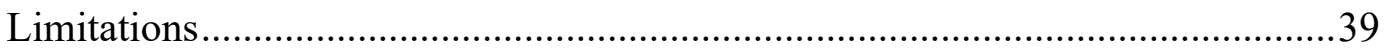

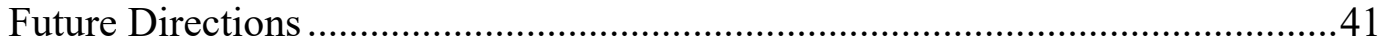

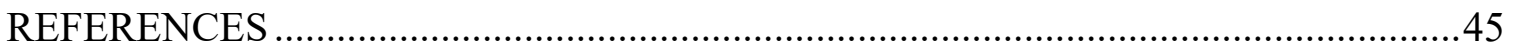

APPENDIX

1. THERAPIST COGNITIVE BEHAVIORAL THERAPY ADHERENCE

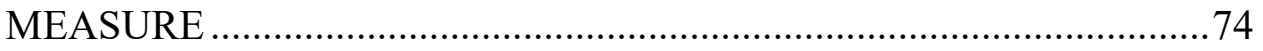

2. CAREGIVER COGNITIVE BEHAVIORAL THERAPY ADHERENCE

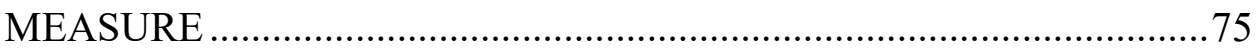

3. YOUTH COGNITIVE BEHAVIORAL THERAPY ADHERENCE

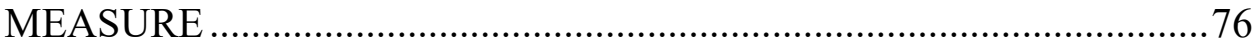




\section{CODER COGNITIVE BEHAVIORAL THERAPY ADHERENCE}

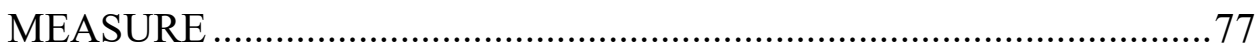

VITA 


\section{LIST OF TABLES}

Table

Page

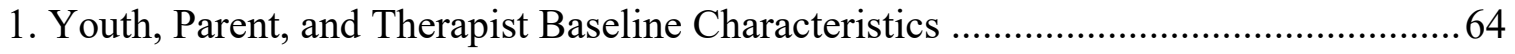

2. Therapist, Parent, Youth, and Coder CBTAM Item Performance ...............................66

3. Therapist, Parent, Youth, and Coder CBTAM Scale and Total Score

Descriptive Statistics

4. Coder-Participant Consistency: ICCs Between Coder-Participant Pairs on CBTAM Items

5. Convergent Validity: Correlations Between Similar Participant-Rated CBTAM and TIEBI Items

6. Convergent Validity: Correlations Between Similar Participant-Rated CBTAM and TPOCS-A Items.

7. Clinical Utility: Multilevel Models of Participant-Rated CBTAM Episode Total Scores Predicting Symptom Improvement Trajectories

8. Clinical Utility: Comparison of Random Intercepts and Slopes vs. Intercepts and Fixed Slopes Models

9. End-of-Treatment CBTAM Correlations with and Coder CBTAM, TIEBI, and TPOCS-A Episode Scores. 


\title{
TOWARD EFFECTIVE AND EFFICIENT TREATMENT ADHERENCE MONITORING: DEVELOPMENT OF THE COGNITIVE BEHAVIORAL THERAPY ADHERENCE MEASURE
}

\author{
Evelyn Cho \\ Dr. Kristin M. Hawley, Dissertation Supervisor
}

\begin{abstract}
Despite the large body of research demonstrating the efficacy of evidence-based practices (EBPs) for the most common youth mental health problems, EBPs are rarely used in usual care (UC). When EBPs are implemented in UC settings, there is a drop in adherence, and sometimes a drop in outcomes. Feasible and practical adherence monitoring tools may support high quality EBP delivery in UC. The current study examined the psychometric properties of the Cognitive-Behavioral Therapy Adherence Measure (CBTAM), a suite of therapist-, parent-, and youth-reported measures of adherence to the core components of cognitive-behavioral therapy (CBT) for youth anxiety, depression, and behavior problems. Therapists, parents, and youths completed the CBTAM after every session throughout a six-session treatment. Coders coded a subset of treatment sessions using the CBTAM and other established observational coding systems for CBT adherence and alliance. Therapists were consistent with coders on their ratings of individual CBTAM items. Therapist, parent, and youth CBTAM item ratings were correlated with similar items on established observational measures of CBT adherence and alliance, and these correlations were higher than correlations between CBTAM items and dissimilar items on observational measures. CBTAM adherence scores predicted faster symptom improvement on some therapist- and parent-rated outcomes. Therapist and parent end-of-treatment ratings were consistent with
\end{abstract}


observational coding measures of adherence and alliance. Findings demonstrate the promise of the CBTAM as a feasible adherence monitoring tool for routine care. 


\section{Introduction}

Over five decades of research demonstrate the efficacy of several specific treatments, or evidence-based practices (EBPs), for common youth mental health problems (i.e., anxiety, depression, and disruptive behavior; Weisz et al., 2017a). Numerous randomized clinical trials (RCTs) consistently document the efficacy of EBPs over waitlist and placebo control groups (e.g., Southam-Gerow \& Prinstein, 2014). A smaller, yet still consistent, body of research of direct comparisons between EBPs and usual care (UC) also indicate the superiority of EBPs over UC (e.g., Weisz et al., 2013). This proliferation of evidence for treating common youth mental health problems, however, has far outpaced the adoption of EBPs in UC settings (e.g., Garland et al., 2010), leaving EBPs an often underutilized tool in the settings where the majority of youths and families access mental health care.

When EBPs are adopted in UC, careful attention to their implementation is needed to maximize their clinical benefit (Fixsen, Naoom, Blasé, Friedman, \& Wallace, 2005). Adherence, the extent to which the treatment is delivered as intended (i.e., the use of prescribed and avoidance of proscribed treatment strategies; Perepletchikova \& Kazdin, 2005), is widely considered a critical component of successful EBP delivery (e.g., Aarons Hurlburt, \& Horwitz, 2011; Damschroder et al., 2009; Fixsen et al., 2005; Proctor et al., 2011), and a necessary precursor to clinical outcomes (e.g., Proctor et al., 2009). Empirical findings also support these notions. Several clinical trials (e.g., Huey, Henggeler, Brondino, \& Pickrel, 2000; Henggeler, Melton, Brondino, Scherer, \& Hanley, 1997) and a recent meta-analysis (Collyer, Eisler, \& Woolgar, 2020) have demonstrated a significant positive relationship between EBP adherence and clinical outcomes. 
Unfortunately, adherence is often suboptimal when EBPs are implemented in UC, independent of a clinical efficacy or effectiveness trial. In clinical trials, adherence is supported via frequent observations of live or recorded treatment sessions by treatment experts (e.g., treatment developers) or trained observer-supervisors in order to ensure internal validity (e.g., Barrett, Healy-Farrell, \& March, 2004; Clarke et al, 1995; Garland \& Schoenwald, 2013; Kendall et al, 1997). Using these methods, adherence is typically high in clinical trials (e.g., Barrett, Healy-Farrell, \& March, 2004; Clarke et al., 1995; Garland \& Schoenwald, 2013; Kendall et al., 1997). However, these gold standard observational methods involve substantial time, financial, and labor costs that are burdensome, even in well-funded trials (Perepletchikova, Hilt, Chereji, \& Kazdin, 2009). Thus, it comes as no surprise that these approaches are rarely employed in UC (Schoenwald \& Garland, 2013), where more than a third of organizations already incur annual budget deficits (Schoenwald et al., 2008).

The absence of monitoring and support for adherence may partially explain the drop in adherence, and the corresponding drop in outcomes, sometimes seen when EBPs are transported to UC settings (Henggeler et al., 1997; Hogue et al., 2008; Huey et al., 2000; McLeod et al., 2019; Sexton \& Turner, 2011; Smith et al., 2017; Southam-Gerow et al., 2016; Taylor, Asgary-Eden, Lee, \& LaRoche, 2015; Weisz et al., 2013). Without a practical means to monitor adherence, UC therapists may lack consistent, reliable feedback to support and guide their implementation of EBPs (Shafran et al., 2009). Without such feedback, their in-session practices may drift far from the EBPs shown successful in so much prior research. Given these theoretical and empirical links between 
adherence and clinical outcomes, monitoring of adherence in UC has been proposed as one strategy to improve EBP implementation (e.g., Lyon, Stannick, \& Pullman, 2017).

\section{Current Adherence Monitoring Methods}

Efforts to implement adherence monitoring in UC will require valid and reliable adherence measures that are also practical to use within UC settings. Unfortunately, adherence monitoring methods to date have largely been dictated by the needs and resources available in RCTs, resulting in methods that are not optimally suited for typical UC settings. A review of adherence monitoring methods for EBPs showed that adherence measures are primarily linked to a specific EBP manual and to each specific edition or iteration of that specific EBP manual (Schoenwald \& Garland, 2013). Detailed treatment manuals are a valuable tool to enhance internal validity. However, given the mismatch between the single-disorder focus of many EBPs (e.g., Addis \& Krasnow, 2000; Powell, Hausman-Stabile, \& McMillen, 2013; Nelson, Steele, \& Mize, 2006) and the complex presentations with multiple co-occurring problems treated by UC therapists (e.g., Ehrenreich-May et al., 2011), EBP manuals are rarely used in UC (e.g., Becker, Smith, \& Jensen-Doss, 2013; Walrath, Sheehan, Holden, Hernandez, \& Blau, 2006). As such, measures designed to assess adherence to one specific treatment manual may not be practically useful to UC therapists who have to respond flexibly to youths' and families' multiple and frequently changing needs (e.g., Weisz et al., 2011; Weisz, Krumholz, Santucci, Thomassin, \& Ng, 2015).

Second, the observational nature of most adherence measures also renders them impractical for UC settings. The aforementioned review of adherence measures found that $72 \%$ of the identified measures were observational, requiring audio or video 
recordings or live observation (Schoenwald \& Garland, 2013). Recordings were coded by study clinicians (23\%), study authors or treatment experts (21\%), or research assistants trained in observational coding (27\%). Approximately $80 \%$ of the observational measures required coding of the entire session, which may have contributed to the large number (79\%) of measures where only a subset of sessions, as opposed to all treatment sessions, were coded. Observational coding also required extensive coder training, taking on average 40 to 60 hours to achieve reliability. After achieving reliability, coders spent between 60 to 90 minutes to complete coding for a single session. Furthermore, coder drift is an ongoing threat to observational coding, requiring continued coder training in order to maintain interrater reliability. Therapists in UC, especially solo or small-group private practices, may not have adequate time or financial resources to purchase recording equipment, to adopt and implement procedures for secure storage and file transfer to the coding team, or to obtain intensive and ongoing training of coders (e.g., Baldwin \& Imel, 2013; Imel et al., 2014). Based on the review by Schoenwald and Garland (2013), coder training alone would require payment for a full standard work week (i.e., 40 to 60 hours) for each coder, followed by actual coding and ongoing meetings to prevent coder drift. Even if such observational coding measures and procedures are adopted in UC, they may not be sustained over time given that infrastructure to support EBP implementation is often cut to manage costs in UC (Weisz, Ng, \& Bearman, 2014).

In addition to the practical barriers posed by the coding of session tapes, the need to observe or record treatment sessions may itself pose procedural and attitudinal barriers. Implementing any new practice can be a hurdle, especially when the new practice 
requires new equipment, new supplies and new procedures. Observational coding necessitates a deviation from normal practices for most UC settings since observation of therapy sessions rarely occurs in UC (e.g., Accurso, Taylor, \& Garland, 2011; Bailin, Bearman, \& Sale, 2018; Dorsey et al., 2018; Lucid et al., 2018), further decreasing the likelihood that observational coding will successfully be implemented and sustained in routine care (Schoenwald et al., 2011). In addition, clients, therapists, and organizations may have concerns about recording therapy sessions (e.g., client confidentiality, secure file storage) and may not agree to record sessions. For example, in a recent study of youth substance abuse treatments in UC, only $35 \%$ of planned recordings were actually submitted to the research team (Hogue, Dauber, Lichvar, Bobek, \& Henderson, 2015). Reasons for missing recordings included families not consenting to recordings (41\%), the clinic not allowing recordings (26\%), and a range of other reasons $(33 \%)$ such as changes in consent to recordings, equipment problems and therapists not turning in recordings for unknown reasons.

\section{Participant-Rated Adherence Measures}

One potential alternative when observational coding is not feasible is the use of participant-rated (e.g., therapist, youth, parent measures) adherence measures (Garland, Bickman, \& Chorpita, 2010; Hogue et al., 2015; McLeod, Southam-Gerow, Tully, Rodriguez, \& Smith, 2013). Participant-rated measures are less costly in terms of time (i.e., 5-15 minutes to complete an adherence checklist versus 60-90 minutes to code a single therapy session) and money (i.e., cost to purchase a measure versus cost to purchase a measure and all equipment to support observational coding and to pay a professional coding team; Schoenwald \& Garland, 2013). Additionally, since participant- 
rated measures do not require recordings of therapy sessions, they also bypass potential client and clinic concerns about having therapy sessions recorded, stored, and viewed by research personnel. Because of their relatively low cost, participant-report measures can also be administered after every session. This allows for the assessment of "infrequent but clinically meaningful” (Hogue, Dauber, Henderson, \& Liddle, 2014, p. 697) treatment components that might be missed if only a subset of sessions were coded.

\section{Informant Discrepancies}

Participant-rated adherence measures are not without limitations, however. Arguably, the most-often noted limitation is the potential for reporter bias. A small but growing number of studies comparing multi-informant adherence measures suggest that therapists tend to overreport their adherence compared to trained observers (e.g., Carroll et al., 2000; Herschell et al., 2019; Hogue et al., 2014; Hurlburt et al., 2010; Martino et al., 2009). However, others have reported good therapist-observer agreement for the presence or absence of specific treatment components (e.g., Martino et al., 2009; Ward et al., 2013) and for the intensity of the implementation of specific treatment components and goals (e.g., Hurlburt et al., 2010).

In fact, informant discrepancies do not necessarily indicate that participantreported adherence measures cannot be valid or useful (Achenbach, 2006). First, discrepancies may arise from different experiences. For example, therapists and youths have "insider information" about what occurs in the therapy room. Parents, on the other hand, often have to rely on what therapist or youth share with them about what occurs in a session or over the course of therapy, or what they see or hear during a parent or family session. Coders must base their ratings of adherence on the just the session, or portion of 
the session, they actually viewed (often a small subset of the treatment episode; Carroll et al., 2000).

Different informants may also have different standards for what constitutes adherent implementation. At least two studies (Chapman, McCart, Letourneau, \& Sheidow, 2013; Herschell et al., 2019) comparing youth, parent, therapist, and trained coders' ratings against treatment expert ratings have found that youths and parents significantly overreported therapist adherence compared to experts and therapists. However, both therapists and trained coders were generally consistent with treatment experts (Chapman et al., 2013). Interestingly, and despite these generally consistent ratings, therapists reported somewhat higher adherence than treatment experts and coders reported somewhat lower adherence than treatment experts. This finding raises the question of whether prior research showing therapists' "overreporting" of adherence compared to trained observers might, at least in part, stem from trained raters' "underreporting" adherence compared to experts (Chapman et al., 2013; Hogue et al., 2014, 2015). Indeed, coders are often trained to code for "standard" implementation (i.e., as prescribed in the manual), and to code for every opportunity the therapist could have delivered a skill (Sheshko, Lee, \& Gagné, 2020). However, therapists often adapt treatment to respond to client needs (e.g., Palinkas et al., 2013). Thus, more flexible, responsive delivery could yield lower adherence ratings from coders looking for "standard" implementation at every possible opportunity, but higher adherence from treatment developers and experts who have more experience with flexible implementation, and even higher adherence from therapists themselves who know what they were trying to implement. Meanwhile, youths and parents are often naïve to both the 
treatment and to adherence rating, and may have a lower threshold for adherence (e.g., rating any mention or suggestion of the technique as adherent).

Lastly, each informant may offer important and unique information about what goes on in the therapy room. For example, youth reports of adherence may reflect what the youth heard and understood in a session, or over the course of treatment. Given that parent involvement may be limited to the beginning and end of sessions (e.g., updates, review of treatment progress or treatment content), parent reports may reflect the treatment components that were shared with the parent at this time. These components may be more likely to be the components emphasized in the session, and thus parent report may be a reflection of the main focus of the session as opposed to therapist delivery of each component on any given measure. Therapist report, on the other hand, may better reflect what the therapist said or did, or intended to say or do. As such, rather than promoting a single "most valid" or "most accurate" informant, it is critical to consider the usefulness of different raters' ratings in order to get a richer picture of treatment adherence. Such an approach parallels what is recommended in youth psychopathology assessment where youths, parents and teachers show limited concurrence but each perspective is important in fully understanding the youth's clinical presentation (e.g., Achenbach, McConaughy, \& Howell, 1987; De Los Reyes \& Kazdin, 2005).

\section{Current Participant-Rated Adherence Measures}

Indeed, there are a growing number of participant-reported adherence measures. Schoenwald and Garland (2013) identified 65 (26\% of all identified measures) participant-rated measures spanning a wide range of youth-, family-, and adult-focused 
EBPs administered to therapists (86\%) and clients (17\%). Many of these measures, like observational coding measures, were also designed to accompany specific, single disorder EBPs (e.g., Multisystemic Therapy Adherence Measure to assess adherence to multisystemic therapy for juvenile delinquency; Schoenwald, Henggeler, Brondino, \& Rowland, 2000). Several such measures are promising and may be worthwhile for UC settings where these specific manuals are being implemented (e.g., MSTAM has shown significant correlations with youth and parent outcomes). However, since specific treatment manuals are used infrequently in UC settings even when implementation supports are in place (e.g., Jensen-Doss, Hawley, Lopez, \& Osterberg, 2009), their accompanying manual-specific adherence measures may have limited relevance to the typical UC therapist.

\section{A Transdiagnostic, Components Approach to Adherence Measurement}

One potential way to address the need for adherence measures that span a wider

range of target problems and populations may be to extend the recent transdiagnostic and common components treatment approaches to adherence measures. Transdiagnostic treatments (e.g., Unified Protocol for Adolescents, Modular Approach to Therapy for Children, FIRST Program for Behavioral and Emotional Problems) target a range of presenting problems (e.g., internalizing concerns) rather than a single diagnosis (e.g., separation anxiety) or problem type (e.g., anxiety). Such treatments have garnered enthusiasm and empirical support in the past decade (e.g., Chorpita et al., 2017; Ehrenreich-May et al., 2017; Weisz et al., 2012). These approaches enable therapists to treat multiple co-occurring problems using a single protocol, thus increasing their practicality in UC settings where comorbidity is often the rule, rather than the exception 
(e.g., Cho et al., 2019). A transdiagnostic adherence measure that assesses adherence to EBPs for the most common youth mental health referral problems may better fit with UC therapists' practice contexts.

Somewhat related to the movement toward transdiagnostic treatments has been the growing recognition that specific EBP manuals targeting a specific problem and population (e.g., anxiety disorders for adolescents) often overlap in much of the prescribed treatment components (Chorpita, Daleiden, \& Weisz, 2005; Garland, Hawley, Brookman-Frazee, \& Hurlburt, 2008). For example, exposure is a component of approximately $90 \%$ of specific EBP manuals for youth anxiety (i.e., exposure is a common component of most EBPs for anxiety; Higa-McMillan et al., 2017).

Furthermore, some of these treatment components are also common across EBPs for different target problems and populations. For example, cognitive restructuring is a common component across numerous specific EBP manuals for anxiety, for depression, and for disruptive behavior among youths aged 8-17 (Chorpita \& Daleiden, 2009). This overlap across problem areas lends further credence to the development of a transdiagnostic and transmanual EBP adherence measure that assesses for the treatment components common across multiple EBP manuals for multiple target problems and populations. In fact, UC therapists tend to incorporate components of different EBP manuals in routine care (e.g., Cho et al., 2019; Higa-McMillan et al., 2017). As such, this approach may better reflect how EBPs are actually implemented in UC, and may be preferred by UC therapists and organizations, over adherence measures for a specific treatment manual. 
At least three groups have begun to design and test therapist-report measures that are transmanual, or focused on common components. Hurlburt and colleagues (Hurlburt, Garland, Nguyen, \& Brookman-Frazee, 2010) developed the Child Therapy Process Rating System to assess for implementation of goals and strategies common across EBP manuals for young children with disruptive behavior problems. Hogue and colleagues (Hogue et al., 2015) developed the Inventory of Therapy Techniques for Adolescent Behavior Problems. Both measures are applicable across EBP manuals, and both have shown some initial psychometric promise, although both remain focused on a single problem area and population. The Monthly Treatment Progress Summary (MTPS; Borntrager, Chorpita, Orimoto, Love, \& Muller, 2015) is a third therapist-report measure that assesses for past-month delivery of 55 treatment components, including the core components of EBPs for the most common youth mental health problems. Should this monthly retrospective report prove reliable and valid, the MTPS is a promising therapistreport measure that is both transmanual and transdiagnostic.

\section{Current Project and Hypotheses}

Building on these exemplars, the Cognitive and Behavioral Therapy Adherence Measure (CBTAM; Hawley, 2013), a participant-rated (i.e., therapist, youth, parent informants) adherence measure was developed to address the need for a brief transdiagnostic and transmanual measure that would not require session recordings or trained coders to support its routine use in UC settings. To enhance its feasibility and relevance to providers treating youths in UC settings, the CBTAM was designed to assess therapist adherence to evidence-based cognitive and behavioral therapies (1) across multiple EBP manuals, (2) for the most common mental health problems (i.e., anxiety, 
depression, disruptive behavior), (3) among both children and adolescents, in a single measure.

The current study describes the initial development of the CBTAM and evaluation of its psychometric properties. In line with common psychometric practice for measures of treatment adherence (e.g., Carroll et al., 2000; Henggeler et al., 1997; Hogue et al., 2008; Southam-Gerow et al., 2016), the aims of the current study were to:

Aim 1. Examine item performance of each CBTAM item across therapists, youths, and parents.

Hypothesis. I did not have a priori hypotheses about item performance. I will present descriptive statistics.

Aim 2. Examine participant-coder consistency between participant-rated and observercoded CBTAMs.

Hypothesis: I hypothesized that therapist CBTAM ratings would reach adequate consistency (i.e., ICC's at or above .40 ) with the observer-coded CBTAM ratings. Given past research showing substantial overreporting by parents and youths relative to trained observer-coders (e.g., Chapman et al., 2013; Herschell et al., 2019), I expected that youth and parent CBTAM ratings would not reach adequate consistency with the observer-coded CBTAM ratings.

Aim 3. Examine convergent and discriminant validity between the therapist, parent, and youth CBTAMs and established measures of treatment adherence.

Hypothesis: I hypothesized that therapist CBTAM ratings would show significant, modest correlations (i.e., $r$ 's at or above .20) with established adherence and alliance measures covering similar content. Consistent with past research (e.g., 
Chapman et al., 2013; Herschell et al., 2019), I expected that youth and parent CBTAM ratings would not correlate significantly with established adherence measures that rely on observer ratings. I also expected that correlations between the CBTAM and similar observational measures would be larger than correlations between the CBTAM and dissimilar observational measures.

Aim 4. Examine the clinical utility of the therapist, youth, and parent CBTAMs. Hypothesis. I hypothesized that higher adherence on participant-rated CBTAMs will predict faster improvement on symptom trajectories.

Aim 5. Examine whether the CBTAM administered once at the end of treatment is comparable to the CBTAM sessions across a treatment episode.

Hypothesis. This was an exploratory aim to better understand how timing of measure administration may be related to adherence ratings. I did not have any a priori hypotheses. 


\section{Method}

\section{Participants}

Youths and Parents. Forty-eight youths and their parents received up to six sessions of CBT for youth anxiety, depression, and disruptive behavior. Youths had a mean age of $11.41(S D=2.61)$ years and were $54.17 \%$ male and $60.42 \%$ White. Based on parent-reported target problems, $62.50 \%$ of youths were referred for anxiety, $47.92 \%$ depression, and $46.88 \%$ behavior problems (these percentages do not add up to $100 \%$ because parents were asked to endorse all problem areas). Parents had a mean age of $42.68(S D=6.02)$ years, were primarily female $(91.67 \%)$, and had at least a college degree $(75.00 \%)$. See Table 1 for a full summary of participant characteristics.

Therapists. Therapists were 28 graduate students in clinical, counseling, and social work programs at a university-affiliated training clinic serving youths and families in the local community. Therapists had a mean age of $29.46(S D=6.36)$ years, and were primarily female $(75.00 \%)$, White $(82.14 \%)$, and had a master's degree $(57.14 \%)$. See Table 1 for a full summary of participant characteristics.

\section{Study Design and Procedures}

Youths and Parents. Parents and youths were recruited via advertisements offering free brief therapy to youths with common mental health problems. Parents who responded to the advertisement were screened by study staff via phone. Youths whose parents reported concerns with anxiety, depression, and/or behavior problems, and who had no past diagnosis of intellectual disability or mental retardation, were scheduled for the pretreatment assessment. At the pretreatment assessment, study staff explained the project, and youths gave assent and parents gave formal consent. Youths and parents also 
completed demographics and symptom measures. Youths and parents then started treatment and completed weekly symptoms and functioning measures and the CBTAM immediately after their treatment sessions. Each participant was paid $\$ 5$ for each weekly battery of measures they completed.

Therapists. Therapists were recruited from graduate training programs in clinical psychology, counseling psychology, and social work at the University of Missouri. Therapists who responded to recruitment letter called the research team and provided formal consent for their participation in the study and completed a form on their demographic and professional characteristics. Therapists received training and supervision from a licensed clinical psychologist with expertise in CBT for youths with anxiety, depression, and disruptive behavior problems. Therapists completed the same weekly symptoms and functioning measures and the CBTAM after each session for each youth they treated.

Treatment. Youths and parents received up to six sessions of therapy focused on common components of EBPs for youth anxiety, depression, and disruptive behavior (Weisz et al., 2017b). The core components included relaxation, cognitive coping, problem-solving, exposure (specific to anxiety), behavioral activation (specific to depression), and behavioral parent training (specific to disruptive behavior).

\section{Measures}

\section{Treatment Adherence Measures.}

Cognitive and Behavioral Therapy Adherence Measure (CBTAM; Hawley,

2013). The CBTAM is a suite of participant-rated measures that assesses therapist adherence to the core components of research-supported CBT for youth anxiety, 
depression, and behavior problems. The CBTAM includes 18 items, each rated on a likert scale from $1=$ "not at all" to $7=$ "a lot".

Initial measure development. Consistent with the procedures outlined by Foster and Cone (1995) and Haynes, Richard, and Kubany (1995) for the development and content validation of behavioral measures, we worked with CBT experts, front line therapists, and youths and parents to establish content, item wording, response format, and scoring and administration procedures for the CBTAM.

To identify core components of CBT for youth anxiety, depression, and disruptive behavior, we followed the procedures by Garland et al. (2008) to identify EBP strategies for disruptive behavior disorders. We first identified CBT protocols for each of the three problem areas from reviews of EBPs (i.e., Burns, Hoagwood, \& Mrazek, 1999; Carr, 2006; Chambless \& Ollendick, 2001; Chambless et al., 1996; Chambless \& Hollon, 1998; Franklin, Foa, Nathan, \& Gorman, 1998; Lonigan et al., 1998; Roth \& Fonagy, 2005; Silverman \& Hinshaw, 2008; Task Force on Promotion and Dissemination of Psychological Procedures, 1995). If a treatment manual was available for any of the identified CBT protocols, we coded the treatment manual for core components. If a treatment manual was not accessible, we coded published RCTs for treatment components. The research team (principal investigator and 11 research assistants) coded 11 protocols for anxiety (3 were for Obsessive-Compulsive Disorder), 11 for disruptive behavior, and 5 for depression. Coders identified the core components of CBT in each protocol, and reached in-house consensus on the core components for each protocol. We retained components that were prescribed in multiple manuals for the given target problem, and shared a list of these core components with an expert consultant for 
additions, modifications, and deletions. This process produced 20 components for anxiety, 22 for depression, 23 for behavior. As expected, many of the components overlapped across the three problem areas (e.g., psychoeducation was prescribed in multiple manuals for anxiety, depression, and behavior). There were also components that were specific to each target problem (i.e., exposure for anxiety, behavioral activation for depression; behavioral parent training for disruptive behavior).

We then used a modified Delphi technique (e.g., Cho et al., 2019; Garland et al., 2008) to obtain broader expert review and consensus on these core components identified by our research team. We identified 90 CBT experts (i.e., treatment developers; 30 for anxiety, 18 for depression, 22 for disruptive behavior) to serve as our subject matter experts (SMEs) and sent the list of core CBT components for their expertise domain (i.e., the target problems). For each CBT component, we asked SMEs to rate "the extent to which you feel that each strategy listed below is an essential component of evidencebased cognitive-behavioral therapy for children and adolescents with [problem area].” Ratings of 0 indicated "not useful or essential," 1 indicated "useful, but not essential," and 2 indicated "essential." We also asked SMEs to add additional core CBT components that were missing from the list. Response rates were as follows: $33.33 \%(n=10)$ for anxiety, $38.89 \%(n=7)$ for depression, and $22.72 \%(n=5)$ for behavior. We examined content validity for each item and for each problem-specific measure using content validity ratios $\left(C V R s ;\right.$ Lawshe, 1975): $C V R=\left(n_{e}-N / 2\right) /(N / 2)$, where $n_{e}$ is the number of SMEs who rated each component as "useful but not essential" or "essential" and $\mathrm{N}$ is the total number of SMEs. CVR values range from -1.00 to 1.00 , with positive values indicating that more than half the SMEs rated the item as "useful but not essential" or 
“essential." We dropped items with CVRs below the specified threshold CVR for the number of SMEs, resulting in 20 components for anxiety, 22 for depression, and 18 for behavior.

To improve content validity and maximize the match between the researcher's intentions for each item and youth, parent, and therapists' interpretations of these items, we interviewed youths, parents, and therapists to assess whether they understood the CBTAM items and the feasibility of the 7-point rating scales items (Haynes et al., 1995; Ware et al., 2003). We recruited 15 youths who were receiving treatment for anxiety, depression, and behavior problems and their parents via advertisements in a universityaffiliated clinic. We also recruited 16 community-based youth mental health therapists with a wide range of experience using CBT by mailing recruitment letters explaining the study to therapists listed in a local public directory. We paid all participants $\$ 50$ for participation in these interviews. We asked youths, parents, and therapists to complete a draft of the CBTAM (with the core components determined by expert consensus) regarding a recent therapy session. Following completion of the CBTAM, we asked all participants for feedback on the CBTAM instructions (e.g., how to make it more clear), their feedback on and interpretation of the individual CBTAM items, the response choices (i.e., the rating scale) for the CBTAM items, and any general or overall feedback. We revised items and response options that failed to convey the appropriate meaning.

We compiled the final 18 items retained across the three problem areas into one brief paper-and-pencil rating form (see Appendix 1, 2, 3). These 18 items reflect the core CBT components for anxiety, depression, and disruptive behavior problems and include (1) items that represent the therapeutic alliance (i.e., relationship with therapist, rationale 
for treatment tasks, treatment goals), (2) items that are common components of CBT for all three problem areas (e.g., cognitive restructuring for all three target problems), and (3) items that are specific to CBT for each of the three target problems (i.e., exposure for anxiety; behavioral activation for depression; and behavioral parent training and parentchild relationship building for disruptive behavior). We created three versions of the CBTAM, one for each participant. Each version had the same 18 items but wording varied depending on the informant (i.e., "you" vs "your therapist" vs "your child"). Informants rated how much $(1=$ "not at all" to $7=$ "a lot") the therapist did each of the 18 components at each session.

Administration. We administered the CBTAM to therapists, youths, and parents after each treatment session $(N=255)$. Study staff were present in the waiting room at the end of session to collect the CBTAM and other study measures. Staff read the CBTAM items to younger children, while parents and therapists completed the CBTAM on their own. Staff were available for any questions about item wording or meaning, though questions were rare. Therapists, youths, and parents also completed an end-of-treatment CBTAM where they reported how much the therapist did each of the 18 components throughout the treatment episode.

Scoring. The CBTAM yields a total score and three scale scores for each treatment session and for the entire treatment episode.

CBTAM Alliance Score. The CBTAM alliance score is the mean of three items: therapeutic relationship, treatment rationale, and treatment goals. The CBTAM session alliance score is the mean of these three items for a given session. The CBTAM episode 
alliance score is the mean of these three items across all sessions in a given treatment episode.

CBTAM Common EBP Score. The CBTAM common EBP score is the mean of 10 items: agenda setting, homework, psychoeducation, reinforcement, future planning, role-play, feelings identification, relaxation, cognitive coping, and problem-solving. The CBTAM session common EBP score is the mean of these 10 items for a given session. The CBTAM episode common EBP score is the mean of these 10 items across all sessions in a given treatment episode.

CBTAM Specific EBP Score. Because the CBTAM includes items that cover CBT components for all three target problems, score calculation varies depending on the youth's target presentation. For youths with anxiety, the CBTAM specific EBP score included the exposure item. For youths with depression, the CBTAM specific EBP score included the behavioral activation item. For youths with disruptive behavior, the CBTAM specific EBP score included the behavioral parent training and parent-child relationship building items. The CBTAM session specific EBP score is the mean of all indicated items for any combination of these target problems for the given session (e.g., if a youth had anxiety and depression, the CBTAM session specific EBP score would be the mean of exposure and behavioral activation for that session). The CBTAM episode specific EBP score is the mean of all indicated items for the youth's presentation across all sessions in the treatment episode.

CBTAM Total Score. The CBTAM total score is the mean of all CBTAM alliance, common EBP, and specific EBP (determined by the youth's presentation) items. The CBTAM session total score is the mean of all these items for a given treatment 
session, and the CBTAM episode total score is the mean of all these items across all sessions in a given treatment episode.

Cognitive-Behavioral Therapy Adherence Measure (CBTAM; Hawley, 2013)Observational Coding. Coders used the CBTAM to observationally code for treatment adherence to allow for assessment of consistency between the observer-coded and participant-rated CBTAMs. Three trained coders used the same 18-item CBTAM to rate adherence to CBT (see Appendix 4). To model the procedures for therapists, parents and youths, the coder "training" was a 45-minute conference call wherein the CBTAM developer read each item on the CBTAM and answered any questions from the coders about item meaning. Of note, these coders were already trained to code adherence using other observational coding systems (see Therapist Integrity in Evidence Based Interventions Coding System section below). We taped all treatment sessions and the coders rated a subset $(N=137)$ of these recorded sessions. The coding team divided sessions into thirds (i.e., the early, middle, and late phases) of treatment, and randomly selected one session from each phase for coding, resulting in their coding half of the sessions for each youth's treatment episode. If three or fewer recordings were available, all sessions were coded. Coders coded for "how much" (scale of 1 to 7) therapists did each of the 18 CBTAM items during the entire treatment session. Scoring was identical to the scoring for the participant-rated CBTAMs. Interrater reliability was poor for assessment and treatment rationale. Interrater reliability across coder pairs for the remaining items ranged from $\operatorname{ICC}(1,1)=.54$ - .96 (fair to excellent agreement; Cichetti, 1994), with a mean of $\operatorname{ICC}(1,1)=.78$ (good agreement). 


\section{Therapist Integrity in Evidence Based Interventions (TIEBI) Coding System}

(Bearman, Herren, \& Weisz, 2012). To examine the convergent validity of the participant-rated CBTAMs, we also included the TIEBI, an observational adherence measure that measures therapist adherence to FIRST, a transdiagnostic CBT approach for youths with anxiety, depression, and/or behavior problems (Weisz et al., 2017b). Specifically, the TIEBI assesses for adherence to 23 components prescribed in EBPs for youth anxiety, depression, behavior problems. As with the observational coding of the CBTAM, the coding team selected one tape from each third of each youth's treatment episode $(N=137)$ for coding. Coder training involved attending, or watching a prerecorded, (1) didactic training for therapists learning to administer FIRST, (2) another training focused on which CBT components are prescribed in FIRST and rated on the TIEBI where the trainer explained each TIEBI item and showed video examples of each of the TIEBI items, (3) coding of practice tapes, (4) followed by review of codes and comparisons with the expert coder, and finally (5) independent coding of the same six therapy sessions. Those coders who demonstrated good reliability (i.e., ICC $\geq .59$ ) then coded recorded therapy sessions. Coders rated the presence/absence of each of the 23 items in five-minute segments for the entire treatment session. We calculated a mean adherence score for each TIEBI item for each coded treatment session by summing the number of five-minute segments in which the given TIEBI item was "present," then multiplying that number by five (i.e., the number of minutes in each segment), dividing by the total session time, and multiplying by 100 (Woo et al., 2018). Reliability across pairs of coders ranged from $\operatorname{ICC}(1,1)=.18-.98$ (poor to excellent agreement), with one item having poor agreement (i.e., treatment rationale $\operatorname{ICC}=.16)$, and a mean of $\operatorname{ICC}(1,1)$ 
$=.80$ (excellent agreement). For the current study, I calculated a TIEBI session adherence score by averaging the session scores for all TIEBI items for a given session. I calculated a TIEBI episode adherence score by averaging the session adherence scores for all TIEBI items for all sessions in the treatment episode.

\section{Therapy Process Observational Coding System-Alliance Scale (TPOCS-A;}

McLeod \& Weisz, 2005). We included the TPOCS-A to examine the convergent validity of the participant-rated CBTAM alliance ratings with established alliance measures. The TPOCS-A is a nine-item observational coding system measuring therapeutic alliance. Coders rated on a six-point scale ( $0=$ "not at all" to $5=$ "a great deal") the extent to which youths and parents demonstrate understanding, hostility, positive affect, and other alliance-related behaviors in each therapy session. For the youth-therapist alliance, ICC $(1,1)=.16-.76$ (poor to excellent agreement), with a mean ICC $(1,1)=.44$ (fair agreement). For the parent-therapist alliance, $\operatorname{ICC}(1,1)=-.35-.86$ (poor to excellent agreement), with mean $\operatorname{ICC}(1,1)=.37$ (poor agreement). For the current study, the TPOCS-A items for a given session were averaged to create a TPOCS-A session alliance score, and a TPOCS-A episode alliance score was calculated by averaging all TPOCS-A items across all sessions in a treatment episode.

\section{Youth Symptoms and Top Problems Measures}

Pre/Post-Treatment Symptoms Measures. At pre- and post-treatment assessments, parents completed the 118-item Child Behavior Checklist (CBCL) and youths the 112-item Youth Self-Report (YSR; Achenbach \& Rescorla, 2001). Both the CBCL and YSR yield internalizing, externalizing, total problem $T$ scores based on youth 
age and gender. There is extensive evidence supporting the psychometrics of the CBCL and YSR (Achenbach \& Rescorla, 2001).

Session-by-Session Symptom and Target Problem Measures. After each treatment session, therapists, parents, and youths completed the 12-item Brief Problem Checklist (BPC; Chorpita et al., 2010) and 3-item Top Problems Assessment (TPA; Weisz et al., 2011). The BPC is a 12 -item standardized measure (ratings of $0=$ "not at all" to 2 = "very much" a problem) including six internalizing and six externalizing items yielding a total score range from 0-24. The TPA is an idiographic measure of selfreported severity on youth- and parent-identified top (Weisz et al., 2011). In the current studies, the TPA was rated on a 0 to 2 scale, consistent with BPC, CBCL, and YSR. Both the BPC and TPA have demonstrated strong psychometric properties (Chorpita et al., 2010; Weisz et al., 2011).

\section{Data Analytic Plan}

Aim 1: Item Performance. I present descriptive statistics on informants' CBTAM individual item ratings, and the CBTAM session and episode scale (alliance, common EBP, specific EBP) and total scores.

Aim 2: Participant-coder consistency. I examined participant-coder consistency on ratings for individual CBTAM items by calculating two-way random intraclass correlations (ICC), single measures, for consistency (McGraw \& Wong, 1996). This ICC model is most appropriate given the design of the study and the specific research questions: (1) the raters in the study are a random sample of all possible raters; (2) a random subset of raters rated each CBTAM item; (3) the goal was to examine consistency for each individual rating as opposed to the average of multiple raters' 
ratings; and (4) consistency (i.e., as ratings for one rater increases, the other's increases as well) between raters may be more appropriate than absolute agreement on ratings (i.e., the same exact number rating for both raters) given previous findings that participantrated adherence is often higher than coder adherence ratings (e.g., Carroll, 1998;

Chapman et al., 2013). I ran all analyses in SPSS 24 using all sessions with observational coding $(N=137)$.

Aim 3: Convergent and Discriminant Validity.

I correlated each individual CBTAM item with similar TIEBI and TPOCS-A items to examine the convergent validity of the participant-rated CBTAM items. Several CBTAM items (i.e., homework, exposure, behavioral parent training) had multiple corresponding TIEBI items, so I correlated those CBTAM items with each relevant TIEBI item. The CBTAM praise item did not have an appropriate corresponding TIEBI item. For discriminant validity, I correlated each individual CBTAM item with dissimilar TIEBI and TPOCS-A items. I hypothesized that correlations between similar CBTAM and TIEBI or TPOCS-A items would be larger than correlations between dissimilar CBTAM and TIEBI and TPOCS-A items. I ran all analyses in SPSS 24 using all sessions that were observationally coded $(N=137)$.

Aim 4: Clinical Utility. To examine the clinical utility of the CBTAM, I examined whether the CBTAM episode scores were associated with faster symptom improvement. The data had a nested structure with measurement occasions $(N=255)$ nested within youths $(N=48)$, who were nested within therapist $(N=29)$. The youth level explained on average $52 \%($ range $=27-75 \%)$ of the variance across outcomes, while the therapist level explained on average $8 \%($ range $=0.00-44 \%)$. Therefore, I ran two- 
level models examining the effects of the CBTAM episode scores (level 2) on trajectories of change across time (measured using days since the baseline assessment; level 1), with random intercepts and slopes for time using restricted maximum likelihood in R ( $\mathrm{R}$ Core Team, 2017). I hypothesized that higher CBTAM episode total scores would predict faster symptom improvement on all symptom measures.

Additionally, I predicted engagement from the CBTAM episode total scores. The engagement variables were treatment completion (completed all six sessions, did not complete all six sessions), no-shows or cancellations (the percentage of scheduled sessions that were not attended as scheduled), and parent participation (the percentage of scheduled sessions where parents were involved in any part of the treatment session). I expected higher CBTAM episode total scores to be associated with higher engagement. I ran all analyses in SPSS 24.

Aim 5: Examine Performance of the End-of-Treatment CBTAM Scores. At the end of treatment, all youths, parent, and therapists completed an End-of-Session CBTAM to rate therapist adherence to $\mathrm{CBT}$ items for the entire treatment episode. To examine whether the end-of-treatment CBTAM could be used as a substitute for weekly ratings to gauge overall adherence to CBT for a given treatment episode, I correlated youth-, parent-, and therapist-reported end-of-treatment CBTAM scores (i.e., total, alliance, common EBP, specific EBP) with coder-rated CBTAM episode scores (i.e., total, alliance, common EBP, specific EBP); TIEBI episode adherence score; and TPOCS-A episode alliance scores. 


\section{Results}

\section{Aim 1: Item Performance}

I present descriptive statistics for each CBTAM item in Table 2. Youths, parents, and therapists endorsed the full range (i.e., 1-7) of possible ratings on all CBTAM items. Psychoeducation, relaxation, exposure, activity scheduling, behavioral parent training and parent-child relationship building were positively skewed, as might be expected since each of these treatment components were typically delivered in only one session.

Treatment rationale and therapeutic relationship were negatively skewed, suggesting that parents, youths and therapists developed a strong working alliance. Items generally included in each session: agenda setting, role play, and homework, were also negatively skewed although these components typically take up a small portion of each session. Overall, parents reported the highest ratings across items, followed by youths, then therapists.

Observational coders also endorsed the full range of possible ratings on all CBTAM items, with the exception of psychoeducation (range =1-4) which failed to hit the ceiling according to coders (see Table 2). Most CBTAM items were skewed positively, as may be expected given that no single CBTAM item should be a major focus of multiple sessions. Overall, coders tended to report lower adherence ratings on all items compared to therapists, youths, and parents.

I present descriptive statistics for therapist-, parent-, youth-, and coder-rated CBTAM scale scores in Table 3. The overall pattern of results for the session and episode scale scores mirrored that of the individual CBTAM items: parents had the highest scale scores, followed by youths, then therapists, then coders. Therapist, parent, and youth, 
CBTAM total scores, alliance scores, and common EBP scores were normally distributed. Coder CBTAM total scores and common EBP scale scores were also normally distributed, but coder alliance scores were positively skewed. All informants' specific EBP scale scores were positively skewed, which may suggest that therapists are not spending adequate time on the treatment components considered the active ingredients of CBT for the given target problem(s).

\section{Aim 2: Participant-Coder Consistency}

I calculated ICCs to examine participant-coder consistency for each CBTAM item (see Table 4). As hypothesized, the average coder-therapist consistency was "fair," $M$ ICC $=.48($ range $=.01-.84)$, with 13 of the 18 items reaching consistency at or above "fair" (reinforcement, homework, future planning, psychoeducation, and assessment had ICC $<0.40$ ). The average coder-parent agreement was "poor", $M \mathrm{ICC}=.28$ (range $=.00-.59)$, with only relaxation, cognitive coping, behavioral parent training, and therapeutic relationship reaching at least "fair" consistency. The average coder-youth agreement was also "poor," $M \mathrm{ICC}=.26$ (range $=.09-.62)$, with only problem-solving and relaxation reaching at least "fair" consistency.

\section{Aim 3: Convergent and Discriminant Validity}

Convergent Validity for CBTAM Items. Therapist-, parent-, and youth-rated CBTAM items were correlated with similar TIEBI and TPOCS-A items (see Tables 5 and 6 for correlations between similar items across measures and informants). As hypothesized, the average correlation between similar coder TIEBI and TPOCS-A and CBTAM items was moderate $\left(M r_{s}=.43\right.$; range $\left.=.11-.78\right)$ for therapists. Contrary to expectations, parent- and youth-rated items were significantly correlated with similar 
TIEBI and TPOCS-A items. The average correlation between similar coder TIEBI and TPOCS-A and CBTAM ratings was moderate for parents $\left(M r_{s}=.30\right.$; range $\left.=-.11-.65\right)$ and small for youths $\left(M r_{s}=.20\right.$; range $\left.=.03-.54\right)$. These results provide support for the convergent validity of the therapist, parent, and youth CBTAMs.

Therapist-, parent-, and youth-rated CBTAM items were correlated with dissimilar TIEBI and TPOCS-A items. The average correlation between dissimilar TIEBI or TPOCS-A and CBTAM items was small $\left(M r_{s}=.12, \min =.07-.19\right)$ for therapists, small $\left(M r_{s}=.11\right.$, range $\left.=.06-.17\right)$ for parents, and did not reach the cutoff for a small association $\left(M r_{s}=.09\right.$, range $\left.=.05-.16\right)$ for youths. As hypothesized, participant-rated CBTAM correlations with similar items were generally larger than correlations with dissimilar items, demonstrating support for the discriminant validity of the therapist, parent, and youth CBTAMs.

\section{Aim 4: Clinical Utility}

Pre/post symptom measures ${ }^{1}$. Multilevel models predicted the trajectory of change for the CBCL and YSR from the CBTAM episode score (see Table 7 for time $\mathrm{x}$ CBTAM regression coefficients). Consistent with hypothesis, therapist CBTAM scores predicted faster CBCL Total and CBCL Externalizing improvement (all $p<.05$ ). However, therapist CBTAM scores did not predict faster CBCL Internalizing, or any YSR trajectories. Higher parent CBTAM scores predicted faster CBCL Externalizing improvement only. Youth CBTAM scores did not predict any of the CBCL and YSR outcome trajectories.

\footnotetext{
${ }^{1}$ These analyses were repeated using random intercept and fixed slopes for time. See Table 8 for coefficients from both models and likelihood ratio test results.
} 
Weekly symptom measures ${ }^{2}$. Multilevel models predicted the trajectory of change for the therapist, youth, and parent BPCs and TPAs from the CBTAM episode score (see Table 7). As hypothesized, higher therapist CBTAM scores predicted therapist TPA improvement (all other predictions $p>.05$ ). The parent CBTAM predicted faster youth BPC improvement (all other predictions nonsignificant). Youth CBTAM scores did not predict rate of improvement for any weekly symptom measures.

Engagement. Regression models predicted engagement variables (i.e., treatment completion, no-show/cancellation rates, and parent participation) from the CBTAM total score (see Table 7). Therapist CBTAM scores predicted treatment completion and noshows/cancellations, but not parent participation. Parent CBTAM scores predicted noshows/cancellations, but not treatment completion or parent participation. Youth CBTAM scores did not predict any of the engagement variables.

\section{Aim 5: Examine Performance of the End-of-Treatment CBTAM Scores}

Therapist end-of-treatment CBTAM scale scores were moderately correlated $(\mathrm{Mr}$ $=.40)$ with corresponding coder CBTAM episode scale scores, and had a small correlation $(M r=.23)$ with similar TIEBI and TPOCS-A episode scores. Parent end-oftreatment CBTAM scores were also moderately correlated $(M r=.39)$ with corresponding coder CBTAM episode scale scores, and moderately correlated $(M r=.41)$ with similar TPOCS-A and TIEBI episode scores. Youth end-of-treatment CBTAM scale scores had a small correlation $(M r=.28)$ with corresponding coder CBTAM scales, and small correlation $(M r=.17)$ with similar TIEBI and TPOCS-A scores. These results provide support for the participant-coder consistency and convergent validity of the therapist and parent end-of-treatment CBTAMs. 


\section{Discussion}

The current study examined the psychometric properties of the CBTAM, a participant-rated measure of therapist adherence to the core components of CBT for youth anxiety, depression, and disruptive behavior problems. The current findings provide some initial support for the participant-coder consistency, convergent validity, and clinical utility of the participant-rated session-by-session, episode, and end-oftreatment CBTAMs.

\section{Participant-Coder Consistency}

The current findings indicate that therapists can reach acceptable levels of consistency with trained coders on their ratings of adherence to the most common components of youth-focused CBT. These results add to the literature highlighting the promise of therapist-rated treatment adherence measures that assess for the presence and absence of treatment components and the degree to which therapists adhere to core treatment components and goals (e.g., Martino et al., 2009; Hurlburt et al., 2010). Given these promising findings, the therapist-rated CBTAM may be a promising alternative to assess for therapist adherence to individual components of CBT on a session-by-session basis when observational coding is not feasible. Given these positive therapist-coder consistency results, one potential use of the therapist CBTAM would be to use it as a measure of adherence to the core components of CBT on a session-by-session basis, and to provide feedback to therapists on their adherence and recommendations for how to improve their adherence.

In line with prior research (e.g., Chapman et al., 2013; Herschell et al., 2019), youth and parent reports of therapist adherence were not consistent with trained coders' 
ratings. It is worth noting that inconsistent ratings are routinely documented in other areas of youth mental health, where discrepant reports are thought to provide perspectives and information unique to each informant (Sheshko et al., 2020). For example, the youth psychopathology literature consistently shows that youths, caregivers, and therapists do not agree on the presence or severity of youth symptoms (e.g., Achenbach et al., 1987) or on target problems for treatment (Hawley \& Weisz, 2003; Yeh \& Weisz, 2001). These discrepant reports are considered reflections of the unique perspectives of each participant, useful for better understanding the youth's symptoms (e.g., only youths can report symptoms only they know, e.g., internalizing problems; De Los Reyes \& Kazdin, 2005). Applied to ratings of treatment adherence, even if youth and parent reports of therapist adherence to the core components of CBT for a given session are not consistent with observer ratings, they may still be useful indicators of what youths or parents heard, understood, or remembered about the content delivered during each session. If conceptualized as indices of session comprehension, parent and youth ratings (even if they are not consistent with coder ratings), could still be useful for providing feedback to therapists. For example, therapists might revisit the treatment components rated highly by therapists indicating that the therapist thought they covered the given content, but were given low ratings by youths or parents indicating youths and parents do not think it was covered). As recommended for youth symptom reports (e.g., De Los Reyes \& Kazdin, 2005), the integration of multi-informant reports may provide a fuller picture of the treatment process.

Aside from these hypothesized results, it is also interesting to consider the variation in participant-coder consistency based on item content. Overall, participant- 
coder consistency tended to be lower on the items reflecting alliance and session procedures, echoing previous findings where participant-rated adherence on CBT procedures were not reliable with observational coding (e.g., Herschell et al., 2019). On the other hand, consistency was higher, even for youths and parents, on CBTAM items that represent CBT skills, or the content of the treatment session. In fact, therapists had "fair" to "good" agreement with coders on all the problem-specific CBT skills considered to be the key ingredients to treatment for all three target problems. Several youth-coder (relaxation, problem-solving) and parent-coder (relaxation, cognitive coping, behavioral parent training, therapeutic relationship). ICCs were also in the fair to good ranges for CBT skills. This is particularly noteworthy given that therapists, youths and parents received no formal training on how to use the CBTAM (and while coders had prior experience rating therapist adherence to $\mathrm{CBT}$, they received only a brief review of CBTAM items and opportunity to ask questions). Further revisions of the CBTAM to include only a subset of items that are more consistently rated by each participant may allow for more efficient administration and scoring of the CBTAM in UC settings where time to monitor adherence may be limited (e.g., Schoenwald \& Garland, 2013). For example, the therapist might rate the entire CBTAM, while youths and parents rate only therapist adherence to CBT skills, or even just the problem-specific CBT skills (i.e., the "active ingredients" of treatment for the given target problem).

\section{Convergent and Discriminant Validity}

The current findings provide preliminary support for the convergent and discriminant validity of the CBTAM items. Therapist-rated CBTAM items showed an average moderate correlation with established, observational measures (with no item 
falling below a "small" correlation), further demonstrating the promise of the therapistreport CBTAM for measuring session-by-session adherence to the core components of CBT. Consistent with hypotheses, the youth- and parent-report CBTAM items had an overall low correlation with the corresponding TIEBI and TPOCS-A items. Correlations between the CBTAM and similar TIEBI and TPOCS-A items were larger than correlations between the CBTAM and dissimilar TIEBI and TPOCS-A items for therapists, parents, and youths, demonstrating the discriminant validity of all three participant-rated CBTAMs.

Consistent with the pattern observed for participant-coder consistency, correlations again tended to be higher across participant-coder pairs on youth-focused CBT skills than on the session procedures. Youths and parents also had moderate correlations with corresponding TIEBI items reflecting CBT skills. Should the parent and youth CBTAM be used to assess adherence to specific CBT components on a session-bysession basis, condensing the youth and parent session CBTAMs to the items with the strongest psychometric support may be worthwhile.

\section{Clinical Utility}

In partial support of the clinical utility of the CBTAM, higher CBTAM episode scores predicted faster symptom improvement for some outcome measures. The therapist CBTAM episode score predicted faster rates of improvement on the CBCL Externalizing score and the therapist-rated TPA. The caregiver-report CBTAM episode score predicted faster rates of improvement on the CBCL Externalizing score and the youth BPC. While the therapist and caregiver CBTAMs predicted faster improvement on some outcome measures, there were no consistent patterns of prediction. This general finding is 
consistent with previous research demonstrating a consistently small, positive relationship between adherence and outcomes for youth psychotherapies (Collyer et al., 2020; Goense et al., 2016; Henggeler et al., 1997; Hogue et al., 2008). That the youthand parent-report CBTAMs did not predict outcomes for the majority of the youth-, caregiver-, and therapist-reported outcomes is also consistent with recent findings on the adherence-outcomes relationship. A small systematic review of five youth CBT therapies found inconsistent adherence-outcomes relationships for youth CBT (Rapley \& Loades, 2018), and a meta-analysis of youth psychotherapies found that client-rated adherence did not predict outcomes (Collyer et al., 2020).

The CBTAM also predicted engagement outcomes. The therapist and parent CBTAM episode scores predicted fewer no-shows and cancellations. This relationship may indicate that youths and parents are more likely to consistently attend treatment when adherence is high, perhaps due to greater "buy-in" of the treatment or due to improved outcomes. However, it may also be that there are more opportunities to deliver more CBT content with youths and parents regularly attend sessions. The therapist CBTAM episode score also predicted treatment completion. Similarly, this finding may simply reflect that there were more opportunities to deliver more of the CBTAM components with longer treatment durations (i.e., capped at six sessions in the current study). As with the symptom outcome trajectories, a true test of the CBTAM's clinical utility will require research on whether receiving feedback using the CBTAM is associated with improved engagement. For example, therapists have reported that discussion of client progress may support shared decision-making for individualized care (Wolpert, Curtis-Tyler, \& Edbrooke-Childs, 2016). This might serve to enhance client 
engagement in treatment. However, youths and parents have reported concerns about how progress monitoring information will be used and whether it determines their access to future services (Edbrooke-Childs et al., 2016). If youths and parents view adherence monitoring as a form of "grading" their therapist or as a determinant of future service access, these perceptions could hurt engagement, but at the same time, provide an opportunity for therapists to collaborate with clients to inform clients about and engage them in evidence-based decision-making and treatment planning.

The clinical utility findings should be interpreted cautiously in light of the study design. The current study was an observational study (like many other studies examining the adherence-outcomes relationship; Webb, DeRubeis, \& Barber, 2010). We did not use an experimental design to manipulate adherence across groups in order to systematically test the effects of adherence on treatment outcomes. As such, the findings may be explained by third variables not measured in the study (e.g., client motivation or response to treatment; Webb, DeRubeis, \& Barber, 2010). In addition, we used the CBTAM episode score to examine clinical utility. The use of a composite score, however, may mask variable effects of the individual items (e.g., perhaps specific item adherence is a stronger predictor of youth outcome than average adherence across all items; Shechtman \& Leichtentritt, 2010). Lastly, the episode score allowed for an initial examination of clinical utility, conceptualized as whether CBTAM scores were associated with improved outcomes across the treatment episode. However, using an adherence score aggregated across the treatment episode on symptom improvement throughout the entire treatment episode does not shed light on how the CBTAM might be used throughout treatment by therapists. For example, if the CBTAM were used to measure adherence at each session 
and to provide feedback to therapists about their adherence regularly throughout treatment, would youths experience greater treatment gains faster? Further research on clinical uses of the CBTAM during treatment (e.g., adherence feedback, informing clinical decision-making and treatment planning) will be crucial to more fully understanding the clinical utility of the CBTAM in real world practice.

\section{Psychometric Properties of the End-of-Treatment CBTAMs}

Recent research suggesting that adherence may change throughout treatment suggests that adherence needs to be coded at multiple timepoints to assess adherence throughout a treatment episode (McLeod et al., 2019). However, repeated observational coding would likely be impractical for most UC settings given the associated costs (e.g., Perepletchikova et al., 2009). This final aim explored whether a single, retrospective CBTAM administered at the end of treatment might be a potential alternative to the session-by-session CBTAM episode scores for gauging how adherent a therapist was to CBT for a given treatment episode.

All participants' end-of-treatment CBTAM scores were correlated with the coder CBTAM episode scores indicating that a single rating provided immediately upon ending therapy may be a worthwhile alternative to session-by-session ratings. Parent end-oftreatment CBTAM scores had the highest and most consistent correlations with coder CBTAM episode scores. Thus, a single parent measure at termination might be a potential efficient option to gauge overall adherence to CBT for the treatment episode. Of note, it is possible that ratings provided only at the end of treatment may be biased by outcomes (e.g., youths and parents who saw substantial improvement may give inflated adherence scores). Should the end-of-treatment CBTAM be used as a single, final 
"check," further research will be needed to determine what score (which may likely differ by informant) would constitute an adequate dose of CBT. Last, the single end-oftreatment CBTAM may not serve as a substitute to session-by-session ratings as it provides no opportunity to course-correct or to address areas of non-adherence, though a therapist could still reflect upon their adherence for a past case in planning for a future case.

\section{General Discussion}

Overall, the findings suggest several potential implications for the various participant-rated CBTAMs. The pattern of results suggests that therapist-reported CBTAMs may be the most reliable and consistent alternative to coder-rated adherence to assess whether and to what degree therapists delivered individual CBT components at each treatment session. The CBTAM ratings taken immediately post-session may be the CBTAM of choice if the purpose is to more feasibly obtain reliable assessment of therapist adherence to specific CBT components on a session-by-session basis throughout a treatment episode. These session-by-session ratings could be used to provide therapists with actionable feedback about whether the treatment components they delivered in a given session were consistent with the evidence base for the target problem(s), and suggestions for other treatment components not yet implemented but are indicated for the specific youth's presentation. Additionally, these session-by-session CBTAM item ratings can be aggregated to gauge how adherent the therapist was to CBT in a given treatment session. These session scores can be further aggregated to assess general adherence to CBT for a treatment episode. Therapist adherence across multiple cases could be also aggregated to gauge how adherent a specific therapist is across clients. 
Parents may not be the most reliable reporters of the implementation of specific CBT components, but session-by-session parent-rated CBTAMs may provide reliable information about how adherent therapists were to CBT overall in a given session and treatment episode. If there are any barriers to parents completing these on a weekly basis, another option for obtaining parent perceptions on treatment process may be to obtain a single CBTAM from the parent at termination. This end-of-treatment CBTAM could serve as a sort of "checklist" for how much CBT was delivered during treatment and how strong the alliance was overall.

The youth-reported CBTAM, including the individual items, scale scores, and the total scores for both treatment sessions and the entire treatment episode, failed to demonstrate acceptable reliability or validity for therapist adherence. If youth perspectives are desired, ratings on a subset of youth-focused CBT skills after each session may have the most psychometric support. Should youth CBTAM ratings be reflective of youth understanding of treatment content, their ratings on all items might still be useful as a check on treatment comprehension and to flag treatment content that the therapist should consider revisiting.

\section{Limitations}

This study had several limitations. As mentioned previously, the observational design, while common in integrity-outcomes research (Webb et al., 2010), precludes definitive conclusions about the clinical utility of the CBTAM. Given that level of adherence was not controlled and randomly assigned, confounding variables may have impacted the relationship between integrity and outcomes in this study. In addition, youths were recruited via advertisements for free therapy and received treatment from 
novice therapists who were trained by a CBT expert and received weekly consultation on how to implement the prescribed CBT components. Without a large TAU sample of clinicians with diverse training backgrounds and the full range of theoretical approaches, providing services as usual to clinically-referred youths within their routine practice setting (e.g., supervision from agency supervisor), the current sample does not provide a true "floor" for CBTAM scores (Rapley \& Loades, 2018). This restriction of range may have impacted the clinical utility results.

Additionally, the CBTAM was designed to address adherence and not other elements of treatment integrity, such as therapist competence or the skillfulness of treatment delivery (Perepletchikova \& Kazdin, 2005). Even if a therapist focused on delivery of a skill for the majority of the session, if delivery of the skill was suboptimal, improved outcomes might not be expected. Further research is needed to better understand the role of competence in treatment outcomes (e.g., Collyer et al., 2020; Webb et al., 2010), and whether there might be clinical utility to including competence items on participant-rated integrity measures, assuming that competence can be reliably and accurately rated by informants without formal and extensive training in the treatment and adherence rating system.

Additionally, not all CBTAM items had directly relevant corresponding items on the TIEBI for convergent validity. As such, the convergent validity of the CBTAM reinforcement item could not be evaluated, and several other CBTAM items (e.g., Assessment) were paired with similar but not truly parallel TIEBI items. Lastly, several youths did not report any target problems, and a specific EBP score could not be calculated for these youths. 


\section{Future Directions}

Moving forward, the current findings and limitations provide several avenues for future research. First, therapists, youths, and caregivers who received minimal training on the CBTAM were able to reach adequate levels of consistency on at least several items with coders who also received minimal training (but had prior experience with coding CBT adherence). Given the intensive training often required for observational coding, that therapists achieved adequate consistency overall and that youths and parents achieved it for some items is promising. Further research is needed on whether enhanced training for youths, caregivers, and therapists may improve agreement (Herschell, 2010). Should increased training improve consistency, it will also be important to identify how much training, and of what kind, is needed for therapists, youths, and parents to reach adequate consistency in UC settings where such training resources may be limited.

Another avenue for research will be further psychometric evaluation of the CBTAM. First, if therapist, youth, and parent CBTAMs all reach adequate consistency with trained coders (e.g., through enhanced training), is there incremental validity in administering the CBTAM to these multiple informants? To date, proponents of multiinformant adherence measures have suggested that participant-rated adherence may not be a substitute for observational coding by experts, but may provide nonoverlapping, unique perspectives that can provide valuable feedback throughout the treatment process (e.g., Herschell et al., 2019). Empirical investigation of this view may inform researchers, practice organizations, and therapists on which informants are best-suited for rating the CBTAM. 
As noted previously, different informants may provide ratings that are useful for different purposes. Further research is needed on the clinical utility of the different CBTAMs. While youth and parent ratings on individual CBTAM items did not reach adequate participant-coder consistency and convergent validity levels, there may be times when clinical utility takes precedence over validity (Haeffel \& Howard, 2010). Youth and parent CBTAM ratings may be useful for providing feedback to therapists. They might serve as a quick check on what the youth or parent took away from or remembered doing during the treatment session, informing the therapist of whether the youth, parent, and therapist are on the same page on the major components delivered in a given session. Parent and youth reports may be particularly helpful for providing feedback to therapists when parent and youth ratings are discrepant from therapist ratings. For example, if youths or caregivers do not report the core treatment content delivered in a given session, these circumstances might reflect poor comprehension of treatment content by the youth or caregiver, or that the therapist did not effectively convey the content in an easily accessible way. For these situations, providing feedback to therapists about discrepant ratings may identify otherwise missed opportunities to maximize client treatment gains. Indeed, routine outcome monitoring of treatment progress, an evidence-based practice on its own, has been shown to identify deterioration and improve outcomes for clients who are not on track to make treatment progress (Shimokawa, Lambert, \& Smart, 2010). Similarly, the CBTAM might be used to identify youths who may not be fully understanding treatment content (assuming that the youth CBTAM is an index of knowledge or comprehension), signaling to therapists to adapt treatment to support improved youth understanding of the treatment content. If feedback using youth and 
parent CBTAM scores predicts improvement in treatment outcomes, administering the CBTAM to these informants (even if there is no support for the consistency of their rating) may have clinical utility. Indeed, in studies where intentional efforts to maintain adherence to the protocol were used, treatment adherence predicted improved outcomes (e.g., Schoenwald, Sheidow, \& Chapman, 2009; Schoenwald, Sheidow, Letourneau, \& Liao, 2003). More recently, quality assurance systems that integrate adherence monitoring and routine progress monitoring have been suggested as potential tools to improve UC practices (e.g., Berkel et al., 2019; Lyon et al., 2017). The CBTAM may be one promising option for inclusion in such systems.

For different uses or purposes of the CBTAM, varied scoring methods will need to be developed and tested. Should the CBTAM be used for decision-making, meaningful cutoffs may be helpful. One option could be to determine the score needed for optimal treatment outcomes, an "integrity-outcome red line" (e.g., Dimidgian et al., 2006; McLeod et al., 2019; Shaw, 1984). For example, one review of youth health prevention and treatment programs found that $60-80 \%$ implementation as intended (including adherence and dosage) was adequate for positive outcomes, and that improvement in implementation beyond this threshold was not associated with significantly better outcomes (Durlak \& DuPre, 2008). On the other hand, if the CBTAM is used to provide feedback to therapists (e.g., Lyon et al., 2017), further examination will be needed to determine what kind feedback is most clinically useful, and at what time points during treatment. For example, a study of CBT for panic disorder in adults found that higher adherence to CBT early in treatment (i.e., first three sessions of a 12-session treatment) was associated with better outcomes (Haug et al., 2016). The current study provided up to 
six sessions of treatment, but with more typical episode lengths, adherence on the CBTAM at different "phases" in treatment may predict outcomes (e.g., symptom improvement, engagement) in subsequent phases. An empirically-derived threshold for individual items may also be helpful. As mentioned previously, the CBTAM individual items could be used to provide feedback to therapists when youths and caregivers provide ratings that are discrepant from therapists' ratings. To provide such feedback, a decisionrule for what counts as a discrepancy is needed.

In conclusion, the current study demonstrates initial promise for the validity and reliability of the therapist CBTAM. The psychometric properties demonstrated in the current study, coupled with its relatively low cost (e.g., minimal training, short administration time) may make the CBTAM a practical and appealing option for measuring adherence to the core components of EBPs for the most common mental health concerns treated in UC. Further evaluation of the psychometric properties of the CBTAM and other practical adherence measures are a much-needed step to developing effective tools that support high-quality services to youths and families in everyday youth mental health care. 


\section{References}

Aarons, G. A., Hurlburt, M., \& Horwitz, S. M. (2011). Advancing a conceptual model of evidence-based practice implementation in public service sectors. Administration and Policy in Mental Health and Mental Health Services Research, 38(1), 4-23. https://doi.org/10.1007/s10488-010-0327-7

Accurso, E. C., Taylor, R. M., \& Garland, A. F. (2011). Evidence-based practices addressed in community-based children's mental health clinical supervision. Training and Education in Professional Psychology, 5(2), 88-96. https://doi.org/10.1037/a0023537

Achenbach, T. M. (2006). As others see us: Clinical and research implications of crossinformant correlations for psychopathology. Current Directions in Psychological Science, 15(2), 94-98. https://doi.org/10.1111/j.0963-7214.2006.00414.x

Achenbach, T. M., McConaughy, S. H., \& Howell, C. T. (1987). Child/adolescent behavioral and emotional problems: implications of cross-informant correlations for situational specificity. Psychological Bulletin, 101(2), 213-232. https://doi.org/10.1037/0033-2909.101.2.213

Achenbach, T. M., \& Rescorla, L. (2001). Manual for the ASEBA school-age forms \& profiles: An integrated system of multi-informant assessment. Burlington, VT: ASEBA.

Addis, M. E., \& Krasnow, A. D. (2000). A national survey of practicing psychologists' attitudes toward psychotherapy treatment manuals. Journal of Consulting and Clinical Psychology, 68(2), 331-339. https://doi.org/10.1037//0022006X.68.2.331 
Bailin, A., Bearman, S. K., \& Sale, R. (2018). Clinical Supervision of Mental Health Professionals Serving Youth: Format and Microskills. Administration and Policy in Mental Health and Mental Health Services Research, 45(5), 800-812. https://doi.org/10.1007/s10488-018-0865-y

Baldwin, S. A., \& Imel, Z. E. (2013). Therapist effects: Findings and methods. In M. J. Lambert (Ed.), Bergin and Garfield's Handbook of Psychotherapy and Behavior Change (5th ed., pp. 258-297). Hoboken, NJ: Wiley.

Barrett, P., Healy-Farrell, L., \& March, J. S. (2004). Cognitive-behavioral family treatment of childhood obsessive-compulsive disorder: a controlled trial. Journal of the American Academy of Child \& Adolescent Psychiatry, 43(1), 46-62. https://doi.org/10.1097/00004583-200401000-00014

Bearman, S. K., Herren, J., \& Weisz, J. R. (2012). Therapy integrity in evidence based interventions: Observational coding system, coding manual. Austin, TX: University of Texas at Austin.

Becker, E. M., Smith, A. M., \& Jensen-Doss, A. (2013). Who's using treatment manuals? A national survey of practicing therapists. Behavior Research and Therapy, 51(10), 706-710. https://doi.org/10.1016/j.brat.2013.07.008

Berkel, C., Gallo, C. G., Sandler, I. N., Mauricio, A. M., Smith, J. D., \& Brown, C. H. (2019). Redesigning implementation measurement for monitoring and quality improvement in community delivery settings. The journal of primary prevention, 40(1), 111-127. https://doi.org/10.1007/s10935-018-00534-z

Borntrager, C. F., Chorpita, B. F., Orimoto, T., Love, A., \& Mueller, C. W. (2015). Validity of clinician's self-reported practice elements on the monthly treatment 
and progress summary. The Journal of Behavioral Health Services \& Research, 42(3), 367-382. https://doi.org/10.1007/s11414-013-9363-x

Burns, B. J., Hoagwood, K., \& Mrazek, P. J. (1999). Effective Treatment for Mental Disorders in Children and Adolescents. Clinical Child and Family Psychology Review, 2(4), 199-254. https://doi.org/10.1023/A:1021826216025

Carroll, K., Nich, C., \& Rounsaville, B. (1998). Utility of therapist session checklists to monitor delivery of coping skills treatment for cocaine abusers. Psychotherapy Research, 8(3), 307-320. https://doi.org/10.1093/ptr/8.3.307

Carroll, K. M., Nich, C., Sifry, R. L., Nuro, K. F., Frankforter, T. L., Ball, S. A., ... \& Rounsaville, B. J. (2000). A general system for evaluating therapist adherence and competence in psychotherapy research in the addictions. Drug and alcohol dependence, 57(3), 225-238. https://doi.org/10.1016/s0376-8716(99)00049-6

Chambless, D. L., \& Hollon, S. D. (1998). Defining Empirically Supported Therapies. Journal of Consulting and Clinical Psychology, 66(1), 7-18. https://doi.org/10.1037//0022-006x.66.1.7

Chambless, D. L., \& Ollendick, T. H. (2001). Empirically supported psychological interventions: controversies and evidence. Annual Review of Psychology, 52, 685716. https://doi.org/10.1146/annurev.psych.52.1.685

Chambless, D. L., Sanderson, W. C., Shoham, V., Bennett Johnson, S., Pope, K. S., \& Crits-Christoph, P. (1996). An update on empirically validated therapies. The Clinical Psychologist, 49, 5-18. https://doi.org/10.1037/e555332011-003

Chapman, J. E., McCart, M. R., Letourneau, E. J., \& Sheidow, A. J. (2013). Comparison of youth, parent, therapist, trained, and treatment expert raters of therapist 
adherence to a substance abuse treatment protocol. Journal of Consulting and Clinical Psychology, 81(4), 674-680. https://doi.org/10.1037/a0033021

Cho, E., Wood, P. K., Taylor, E. K., Hausman, E. M., Andrews, J. H., \& Hawley, K. M. (2019). Evidence-based treatment strategies in youth mental health services: Results from a national survey of therapists. Administration and Policy in Mental Health and Mental Health Services Research, 46(1), 71-81. https://doi.org/10.1007/s10488-018-0896-4

Chorpita, B. F., \& Daleiden, E. L. (2009). Mapping evidence-based treatments for children and adolescents: Application of the distillation and matching model to 615 treatments from 322 randomized trials. Journal of Consulting and Clinical Psychology, 77(3), 566-579. https://psycnet.apa.org/doi/10.1037/a0014565

Chorpita, B. F., Daleiden, E. L., Park, A. L., Ward, A. M., Levy, M. C., Cromley, T., ... \& Krull, J. L. (2017). Child STEPs in California: A cluster randomized effectiveness trial comparing modular treatment with community implemented treatment for youth with anxiety, depression, conduct problems, or traumatic stress. Journal of Consulting and Clinical Psychology, 85(1), 13-25. https://psycnet.apa.org/doi/10.1037/ccp0000133

Chorpita, B. F., Daleiden, E. L., \& Weisz, J. R. (2005). Identifying and selecting the common elements of evidence based interventions: A distillation and matching model. Mental Health Services Research, 7(1), 5-20. https://doi.org/10.1007/s11020-005-1962-6

Chorpita, B. F., Reise, S., Weisz, J. R., Grubbs, K., Becker, K. D., \& Krull, J. L. (2010). Evaluation of the Brief Problem Checklist: Child and parent interviews to 
measure clinical progress. Journal of Consulting and Clinical Psychology, 78(4), 526-536. https://doi.org/10.1037/a0019602

Cicchetti, D. V. (1994). Guidelines, criteria, and rules of thumb for evaluating normed and standardized assessment instruments in psychology. Psychological Assessment, 6(4), 284-290. https://doi.org/10.1037//1040-3590.6.4.284

Clarke, G. N., Hawkins, W., Murphy, M., Sheeber, L. B., Lewinsohn, P. M., \& Seeley, J. R. (1995). Targeted prevention of unipolar depressive disorder in an at-risk sample of high school adolescents: A randomized trial of a group cognitive intervention. Journal of the American Academy of Child \& Adolescent Psychiatry, 34(3), 312-321. https://doi.org/10.1097/00004583-199503000-00016

Collyer, H., Eisler, I., \& Woolgar, M. (2019). Systematic literature review and metaanalysis of the relationship between adherence, competence and outcome in psychotherapy for children and adolescents. European Child \& Adolescent Psychiatry, 29(4), 417-431. doi:10.1007/s00787-018-1265-2

Damschroder, L. J., Aron, D. C., Keith, R. E., Kirsh, S. R., Alexander, J. A., \& Lowery, J. C. (2009). Fostering implementation of health services research findings into practice: a consolidated framework for advancing implementation science. Implementation Science, 4(1), 50. https://doi.org/10.1186/1748-5908-450

De Los Reyes, A., \& Kazdin, A. E. (2005). Informant discrepancies in the assessment of childhood psychopathology: a critical review, theoretical framework, and recommendations for further study. Psychological Bulletin, 131(4), 483-509. https://doi.org/10.1037/0033-2909.131.4.483 
Dimidjian, S., Hollon, S. D., Dobson, K. S., Schmaling, K. B., Kohlenberg, R. J., Addis, M. E., ... \& Atkins, D. C. (2006). Randomized trial of behavioral activation, cognitive therapy, and antidepressant medication in the acute treatment of adults with major depression. Journal of consulting and clinical psychology, 74(4), 658670. https://doi.org/10.1037/0022-006X.74.4.658

Dorsey, S., Kerns, S. E., Lucid, L., Pullmann, M. D., Harrison, J. P., Berliner, L., ... \& Deblinger, E. (2018). Objective coding of content and techniques in workplacebased supervision of an EBT in public mental health. Implementation Science, 13(1), 19. https://doi.org/10.1186/s13012-017-0708-3

Durlak, J. A., \& DuPre, E. P. (2008). Implementation matters: A review of research on the influence of implementation on program outcomes and the factors affecting implementation. American journal of community psychology, 41(3-4), 327-350. https://doi.org/10.1007/s10464-008-9165-0

Ehrenreich-May, J., Rosenfield, D., Queen, A. H., Kennedy, S. M., Remmes, C. S., \& Barlow, D. H. (2017). An initial waitlist-controlled trial of the unified protocol for the treatment of emotional disorders in adolescents. Journal of Anxiety Disorders, 46, 46-55. https://doi.org/10.1016/j.janxdis.2016.10.006 Ehrenreich-May, J., Southam-Gerow, M. A., Hourigan, S. E., Wright, L. R., Pincus, D. B., \& Weisz, J. R. (2011). Characteristics of anxious and depressed youth seen in two different clinical contexts. Administration and Policy in Mental Health and Mental Health Services Research, 38(5), 398-411. https://doi.org/10.1007/s10488-010-0328-6 
Fixsen, D. L., Naoom, S. F., Blase, K. A., Friedman, R. M., \& Wallace, F. (2005). Implementation research: a synthesis of the literature. Tampa, FL: National Implementation Research Network.

Foster, S. L., \& Cone, J. D. (1995). Validity issues in clinical assessment. Psychological Assessment, 7(3), 248-260. https://doi.org/10.1037//1040-3590.7.3.248

Franklin, M. E., Foa, E. B., Nathan, P. E., \& Gorman, J. M. (Eds.). (1998). A Guide to Treatments that Work. New York: Oxford.

Garland, A. F., Brookman-Frazee, L., Hurlburt, M. S., Accurso, E. C., Zoffness, R. J., Haine-Schlagel, R., \& Ganger, W. (2010). Mental health care for children with disruptive behavior problems: A view inside therapists' offices. Psychiatric Services, 61(8), 788-795. https://doi.org/10.1176/appi.ps.61.8.788

Garland, A. F., Bickman, L., \& Chorpita, B. F. (2010). Change what? Identifying quality improvement targets by investigating usual mental health care. Administration and Policy in Mental Health and Mental Health Services Research, 37(1-2), $15-$ 26. https://doi.org/10.1007/s10488-010-0279-y

Garland, A. F., Hawley, K. M., Brookman-Frazee, L., \& Hurlburt, M. S. (2008). Identifying common elements of evidence-based psychosocial treatments for children's disruptive behavior problems. Journal of the American Academy of Child \& Adolescent Psychiatry, 47(5), 505-514. https://doi.org/10.1097/chi.0b013e31816765c2

Goense, P. B., Assink, M., Stams, G. J., Boendermaker, L., \& Hoeve, M. (2016). Making 'what works' work: A meta-analytic study of the effect of treatment integrity on outcomes of evidence-based interventions for juveniles with antisocial 
behavior. Aggression and Violent Behavior, 31, 106-115.

https://doi.org/10.1016/j.avb.2016.08.003

Haeffel, G. J., \& Howard, G. S. (2010). Self-report: Psychology’s four-letter word. American Journal of Psychology, 123(2), 181-188.

https://doi.org/10.5406/amerjpsyc.123.2.0181

Haug, T., Nordgreen, T., Öst, L. G., Tangen, T., Kvale, G., Hovland, O. J., ... \& Havik, O. E. (2016). Working alliance and competence as predictors of outcome in cognitive behavioral therapy for social anxiety and panic disorder in adults. Behaviour Research and Therapy, 77, 40-51.

https://doi.org/10.1016/j.brat.2015.12.004

Hawley, K. M. (2013). Cognitive-Behavioral Therapy Adherence Measures. University of Missouri.

Haynes, S. N., Richard, D., \& Kubany, E. S. (1995). Content validity in psychological assessment: A functional approach to concepts and methods. Psychological Assessment, 7(3), 238-247. https://doi.org/10.1037//1040-3590.7.3.238

Henggeler, S. W., Melton, G. B., Brondino, M. J., Scherer, D. G., \& Hanley, J. H. (1997). Multisystemic therapy with violent and chronic juvenile offenders and their families: the role of treatment fidelity in successful dissemination. Journal of Consulting and Clinical Psychology, 65(5), 821-833. https://doi.org/10.1037//0022-006x.65.5.821

Herschell, A. D. (2010). Fidelity in the field: developing infrastructure and fine-tuning measurement. Clinical Psychology: Science and Practice, 17(3), 253-257. https://doi.org/10.1111/j.1468-2850.2010.01216.x 
Herschell, A. D., Quetsch, L. B., \& Kolko, D. J. (2019). Measuring Adherence to Key Teaching Techniques in an Evidence-Based Treatment: A Comparison of Parent, Therapist, and Behavior Observation Ratings. Journal of Emotional and Behavioral Disorders, 1-12. https://doi.org/10.1177/1063426618821901

Higa-McMillan, C., Kotte, A., Jackson, D., \& Daleiden, E. L. (2017). Overlapping and non-overlapping practices in usual and evidence-based care for youth anxiety. The journal of behavioral health services \& research, 44(4), 684-694. https://doi.org/10.1007/s11414-016-9502-2

Hogue, A., Dauber, S., Henderson, C. E., \& Liddle, H. A. (2014). Reliability of therapist self-report on treatment targets and focus in family-based intervention. Administration and Policy in Mental Health and Mental Health Services Research, 41(5), 697-705. https://doi.org/10.1007/s10488-013-0520-6

Hogue, A., Dauber, S., Lichvar, E., Bobek, M., \& Henderson, C. E. (2015). Validity of therapist self-report ratings of fidelity to evidence-based practices for adolescent behavior problems: Correspondence between therapists and observers. Administration and Policy in Mental Health and Mental Health Services Research, 42(2), 229-243. https://doi.org/10.1007/s10488-014-0548-2

Hogue, A., Henderson, C. E., Dauber, S., Barajas, P. C., Fried, A., \& Liddle, H. A. (2008). Treatment adherence, competence, and outcome in individual and family therapy for adolescent behavior problems. Journal of Consulting and Clinical Psychology, 76(4), 544-555. https://doi.org/10.1037/0022-006x.76.4.544

Huey Jr, S. J., Henggeler, S. W., Brondino, M. J., \& Pickrel, S. G. (2000). Mechanisms of change in multisystemic therapy: reducing delinquent behavior through therapist 
adherence and improved family and peer functioning. Journal of Consulting and Clinical psychology, 68(3), 451-467. https://doi.org/10.1037//0022-006X.68.3.451

Hurlburt, M. S., Garland, A. F., Nguyen, K., \& Brookman-Frazee, L. (2010). Child and family therapy process: Concordance of therapist and observational perspectives. Administration and Policy in Mental Health and Mental Health Services Research, 37(3), 230-244. https://doi.org/10.1007/s10488-009-0251-x

Imel, Z. E., Baldwin, S. A., Baer, J. S., Hartzler, B., Dunn, C., Rosengren, D. B., \& Atkins, D. C. (2014). Evaluating therapist adherence in motivational interviewing by comparing performance with standardized and real patients. Journal of Consulting and Clinical Psychology, 82, 472-481. https://doi.org/10.1037/a0036158

Jensen-Doss, A., Hawley, K. M., Lopez, M., \& Osterberg, L. D. (2009). Using evidencebased treatments: The experiences of youth therapists working under a mandate. Professional Psychology: Research and Practice, 40(4), 417-424. https://doi.org/10.1037/a0014690

Kendall, P. C., Flannery-Schroeder, E., Panichelli-Mindel, S. M., Southam-Gerow, M., Henin, A., \& Warman, M. (1997). Therapy for youths with anxiety disorders: A second randomized clinical trial. Journal of Consulting and Clinical Psychology, 65(3), 366-380. https://doi.org/10.1037//0022-006x.65.3.366

Lawshe, C.H. (1975). A quantitative approach to content validity. Personnel Psychology, 28, 563-575. https://doi.org/10.1111/j.1744-6570.1975.tb01393.x 
Lonigan, C. J., Elbert, J. C., \& Johnson, S. B. (1998). Empirically supported psychosocial interventions for children: An overview. Journal of Clinical Child Psychology, 27(2), 138-145. https://doi.org/10.1207/s15374424jccp2702

Lucid, L., Meza, R., Pullmann, M. D., Jungbluth, N., Deblinger, E., \& Dorsey, S. (2018). Supervision in community mental health: understanding intensity of EBT focus. Behavior Therapy, 49(4), 481-493. https://doi.org/10.1016/j.beth.2017.12.007

Lyon, A. R., Stanick, C., \& Pullmann, M. D. (2018). Toward high-fidelity treatment as usual: Evidence-based intervention structures to improve usual care psychotherapy. Clinical Psychology: Science and Practice, 25(4), e12265. https://doi.org/10.1111/cpsp.12265

Martino, S., Ball, S., Nich, C., Frankforter, T. L., \& Carroll, K. M. (2009).

Correspondence of motivational enhancement treatment integrity ratings among therapists, supervisors, and observers. Psychotherapy Research, 19(2), 181-193. https://doi.org/10.1080/10503300802688460

McGraw, K. O., \& Wong, S. P. (1996). Forming inferences about some intraclass correlation coefficients. Psychological methods, 1(1), 30-46. https://psycnet.apa.org/doi/10.1037/1082-989X.1.1.30

McLeod, B. D., Southam-Gerow, M. A., Jensen-Doss, A., Hogue, A., Kendall, P. C., \& Weisz, J. R. (2019). Benchmarking treatment adherence and therapist competence in individual cognitive-behavioral treatment for youth anxiety disorders. Journal of Clinical Child \& Adolescent Psychology, 48(sup1), S234-S246.

https://doi.org/10.1080/15374416.2017.1381914 
McLeod, B. D., Southam-Gerow, M. A., Tully, C. B., Rodriguez, A., \& Smith, M. M. (2013). Making a case for treatment integrity as a psychosocial treatment quality indicator for youth mental health care. Clinical Psychology: Science and Practice, 20(1), 14-32. https://doi.org/10.1111/cpsp.12020

McLeod, B. D., \& Weisz, J. R. (2005). The therapy process observational coding systemalliance scale: measure characteristics and prediction of outcome in usual clinical practice. Journal of Consulting and clinical Psychology, 73(2), 323-333. https://doi.org/10.1037/0022-006x.73.2.323

Nelson, T. D., Steele, R. G., \& Mize, J. A. (2006). Practitioner attitudes toward evidencebased practice: Themes and challenges. Administration and Policy in Mental Health and Mental Health Services Research, 33(3), 398-409. https://doi.org/10.1007/s10488-006-0044-4

Palinkas, L. A., Weisz, J. R., Chorpita, B. F., Levine, B., Garland, A. F., Hoagwood, K. E., \& Landsverk, J. (2013). Continued use of evidence-based treatments after a randomized controlled effectiveness trial: A qualitative study. Psychiatric Services, 64(11), 1110-1118. https://doi.org/10.1176/appi.ps.004682012

Perepletchikova, F., Hilt, L. M., Chereji, E., \& Kazdin, A. E. (2009). Barriers to implementing treatment integrity procedures: survey of treatment outcome researchers. Journal of Consulting and Clinical Psychology, 77(2), 212-218. https://doi.org/10.1037/a0015232

Perepletchikova, F., \& Kazdin, A. E. (2005). Treatment integrity and therapeutic change: Issues and research recommendations. Clinical Psychology: Science and Practice, 12(4), 365-383. https://doi.org/10.1093/clipsy.bpi045 
Powell, B. J., Hausmann-Stabile, C., \& McMillen, J. C. (2013). Mental health clinicians' experiences of implementing evidence-based treatments. Journal of evidencebased social work, 10(5), 396-409. https://doi.org/10.1080/15433714.2012.664062

Proctor, E., Silmere, H., Raghavan, R., Hovmand, P., Aarons, G., Bunger, A., ... \& Hensley, M. (2011). Outcomes for implementation research: conceptual distinctions, measurement challenges, and research agenda. Administration and Policy in Mental Health and Mental Health Services Research, 38(2), 65-76. https://doi.org/10.1007/s10488-010-0319-7

Rapley, H. A., \& Loades, M. E. (2019). A systematic review exploring therapist competence, adherence, and therapy outcomes in individual CBT for children and young people. Psychotherapy Research, 29(8), 1010-1019. https://doi.org/10.1080/10503307.2018.1464681

Roth, A., \& Fonagy, P. (2005). What works for whom: A critical review of psychotherapy research (2nd ed.). New York: Guildford Publications.

Schoenwald, S. K., Chapman, J. E., Kelleher, K., Hoagwood, K. E., Landsverk, J., Stevens, J., ... \& Research Network on Youth Mental Health. (2008). A survey of the infrastructure for children's mental health services: Implications for the implementation of empirically supported treatments (ESTs). Administration and Policy in Mental Health and Mental Health Services Research, 35(1-2), 84-97. https://doi.org/10.1007/s10488-007-0147-6 
Schoenwald, S. K., \& Garland, A. F. (2013). A review of treatment adherence measurement methods. Psychological Assessment, 25(1), 146-156. https://doi.org/10.1037/a0029715

Schoenwald, S. K., Garland, A. F., Chapman, J. E., Frazier, S. L., Sheidow, A. J., \& Southam-Gerow, M. A. (2011). Toward the effective and efficient measurement of implementation fidelity. Administration and Policy in Mental Health and Mental Health Services Research, 38(1), 32-43. https://doi.org/10.1037/a0029715

Schoenwald, S. K., Henggeler, S. W., Brondino, M. J., \& Rowland, M. D. (2000). Multisystemic therapy: Monitoring treatment fidelity. Family Process, 39(1), 83103. https://doi.org/10.1111/j.1545-5300.2000.39109.x

Schoenwald, S. K., Sheidow, A. J., \& Chapman, J. E. (2009). Clinical supervision in treatment transport: Effects on adherence and outcomes. Journal of Consulting and Clinical Psychology, 77(3), 410-421. https://psycnet.apa.org/doi/10.1037/a0013788

Schoenwald, S. K., Sheidow, A. J., Letourneau, E. J., \& Liao, J. G. (2003). Transportability of multisystemic therapy: Evidence for multilevel influences. Mental health services research, 5(4), 223-239. https://doi.org/10.1023/A:1026229102151

Sexton, T., \& Turner, C. W. (2010). The effectiveness of functional family therapy for youth with behavioral problems in a community practice setting. Journal of Family Psychology, 24(3), 339-348. doi:10.1037/a0019406

Shafran, R., Clark, D. M., Fairburn, C. G., Arntz, A., Barlow, D. H., Ehlers, A., ... \& Salkovskis, P. M. (2009). Mind the gap: Improving the dissemination of 
CBT. Behavior Research and Therapy, 47(11), 902-909.

https://doi.org/10.1016/j.brat.2009.07.003

Shaw, B. F. (1984). Specification of the training and evaluation of cognitive therapists for outcome studies. In J. Williams \& R. Spitzer (Eds.), Psychotherapy research: Where are we and where should we go? (pp. 173-188). New York, NY: Guilford Press.

Shechtman, Z., \& Leichtentritt, J. (2010). The association of process with outcomes in child group therapy. Psychotherapy Research, 20(1), 8-21. https://doi.org/10.1080/10503300902926562

Sheshko, D. M., Lee, C. M., \& Gagné, M.-H. (2020). Multimethod adherence measurement in an evidence-based parenting program. Practice Innovations. Advance online publication. https://doi.org/10.1037/pri0000110

Shimokawa, K., Lambert, M. J., \& Smart, D. W. (2010). Enhancing treatment outcome of patients at risk of treatment failure: meta-analytic and mega-analytic review of a psychotherapy quality assurance system. Journal of consulting and clinical psychology, 78(3), 298-311. https://psycnet.apa.org/doi/10.1037/a0019247

Silverman, W. K., \& Hinshaw, S. P. (2008). The Second Special Issue on EvidenceBased Psychosocial Treatments for Children and Adolescents: A 10-Year Update. Journal of Clinical Child \& Adolescent Psychology, 37(1), 1-7. https://doi.org/10.1080/15374410701817725

Smith, M. M., McLeod, B. D., Southam-Gerow, M. A., Jensen-Doss, A., Kendall, P. C., \& Weisz, J. R. (2017). Does the delivery of CBT for youth anxiety differ across 
research and practice settings?. Behavior Therapy, 48(4), 501-516. https://doi.org/10.1016/j.beth.2016.07.004

Southam-Gerow, M. A., McLeod, B. D., Arnold, C. C., Rodríguez, A., Cox, J. R., Reise, S. P., ... \& Kendall, P. C. (2016). Initial development of a treatment adherence measure for cognitive-behavioral therapy for child anxiety. Psychological Assessment, 28(1), 70-80. https://doi.org/10.1037/pas0000141

Southam-Gerow, M. A., \& Prinstein, M. J. (2014). Evidence base updates: The evolution of the evaluation of psychological treatments for children and adolescents. Journal of Clinical Child \& Adolescent Psychology, 43(1), 1-6. https://doi.org/10.1080/15374416.2013.855128

Task Force on Promotion and Dissemination of Psychological Procedures. (1995). Training in and dissemination of empirically-validated psychological treatment: Report and recommendations. The Clinical Psychologist, 48(1), 2-23. https://doi.org/10.1037/e554972011-003

Taylor, W. D., Asgary-Eden, V., Lee, C. M., \& LaRoche, K. J. (2015). Service therapists' adherence to an evidence-based parenting program: What are they missing and why?. Journal of Child and Family Studies, 24(1), 50-56. https://doi.org/10.1007/s10826-013-9812-4

Walrath, C. M., Sheehan, A. K., Holden, E. W., Hernandez, M., \& Blau, G. (2006). Evidence-based treatments in the field: A brief report on therapist knowledge, implementation, and practice. The Journal of Behavioral Health Services \& Research, 33(2), 244-253. https://doi.org/10.1007/s11414-005-9008-9 
Ward, A. M., Regan, J., Chorpita, B. F., Starace, N., Rodriguez, A., Okamura, K., ... \& Research Network on Youth Mental Health. (2013). Tracking evidence based practice with youth: Validity of the MATCH and Standard Manual Consultation Records. Journal of Clinical Child \& Adolescent Psychology, 42(1), 44-55. https://doi.org/10.1080/15374416.2012.700505

Ware, N.C., Dickey, B., Tugenberg, T. \& McHorney, C.A. (2003). CONNECT: A measure of continuity of care in mental health services. Mental Health Services Research, 5, 209-221. https://doi.org/10.1023/A:1026276918081

Webb, C. A., DeRubeis, R. J., \& Barber, J. P. (2010). Therapist adherence/competence and treatment outcome: A meta-analytic review. Journal of consulting and clinical psychology, 78(2), 200-211. https://doi.org/10.1037/a0018912

Weisz, J., Bearman, S. K., Santucci, L. C., \& Jensen-Doss, A. (2017). Initial test of a principle-guided approach to transdiagnostic psychotherapy with children and adolescents. Journal of Clinical Child \& Adolescent Psychology, 46(1), 44-58. https://doi.org/10.1080/15374416.2016.1163708

Weisz, J. R., Chorpita, B. F., Palinkas, L. A., Schoenwald, S. K., Miranda, J., Bearman, S. K., ... \& Gray, J. (2012). Testing standard and modular designs for psychotherapy treating depression, anxiety, and conduct problems in youth: A randomized effectiveness trial. Archives of General Psychiatry, 69(3), 274-282. https://doi.org/10.1001/archgenpsychiatry.2011.147

Weisz, J. R., Chorpita, B. F., Frye, A., Ng, M. Y., Lau, N., Bearman, S. K., ... \& Hoagwood, K. E. (2011). Youth top problems: Using idiographic, consumerguided assessment to identify treatment needs and to track change during 
psychotherapy. Journal of Consulting and Clinical Psychology, 79(3), 369-380. https://doi.org/10.1037/a0023307

Weisz, J. R., Krumholz, L. S., Santucci, L., Thomassin, K., \& Ng, M. Y. (2015).

Shrinking the gap between research and practice: Tailoring and testing youth psychotherapies in clinical care contexts. Annual Review of Clinical Psychology, 11, 139-163. https://doi.org/10.1146/annurev-clinpsy-032814-112820

Weisz, J. R., Kuppens, S., Eckshtain, D., Ugueto, A. M., Hawley, K. M., \& Jensen-Doss, A. (2013). Performance of evidence-based youth psychotherapies compared with usual clinical care: a multilevel meta-analysis. JAMA psychiatry, 70(7), 750-761. https://doi.org/10.1001/jamapsychiatry.2013.1176

Weisz, J. R., Kuppens, S., Ng, M. Y., Eckshtain, D., Ugueto, A. M., Vaughn-Coaxum, R., ... \& Weersing, V. R. (2017). What five decades of research tells us about the effects of youth psychological therapy: a multilevel meta-analysis and implications for science and practice. American Psychologist, 72(2), 79-117. https://doi.org/10.1037/a0040360

Weisz, J. R., Ng, M. Y., \& Bearman, S. K. (2014). Odd couple? Reenvisioning the relation between science and practice in the dissemination-implementation era. Clinical Psychological Science, 2(1), 58-74. https://doi.org/10.1177/2167702613501307

Wolpert, M., Curtis-Tyler, K., \& Edbrooke-Childs, J. (2016). A qualitative exploration of patient and clinician views on patient reported outcome measures in child mental health and diabetes services. Administration and Policy in Mental Health and 
Mental Health Services Research, 43(3), 309-315.

https://doi.org/10.1007/s10488-014-0586-9 
Table 1

Youth, Parent, and Therapist Baseline Characteristics

Youth and Family Characteristics

$M$ Youth Age $(S D)$

$11.41(2.61)$

$\%$ Youth Male

$54.17 \%$

$\%$ Race

Caucasian/White

$60.42 \%$

Asian American/Pacific Islander

$6.25 \%$

African American/Black

$4.17 \%$

Native American/American Indian

$2.08 \%$

Multiracial

$16.67 \%$

Unreported

$10.41 \%$

$\%$ Latin-x

$6.25 \%$

$M$ Parent Age $(S D)$

42.67 (6.02)

$\%$ Parent Female

$91.67 \%$

Parent Highest Degree

High School Diploma

$22.92 \%$

College Degree

$47.92 \%$

Post-College Degree

$27.08 \%$

$\%$ Biological Child

$93.75 \%$

Primary Presenting Concerns ${ }^{\mathrm{a}}$

Anxiety

$62.50 \%$

Depression

$47.92 \%$

Behavior

$46.88 \%$

Pretreatment Means (SD)

BPC-Parent

$6.13(3.05)$

BPC-Youth

$6.30(4.03)$

TPA-Parent ${ }^{\mathrm{b}}$

$1.33(0.50)$

TPA-Youth ${ }^{\mathrm{b}}$

$1.34(0.53)$

CBCL Total Problems

58.85 (7.21)

YSR Total Problems

$56.64(10.81)$

CBCL Internalizing

$61.30(8.31)$

YSR Internalizing

$56.71(10.24)$

CBCL Externalizing

55.68 (8.37)

YSR Externalizing

$51.90(11.20)$

Therapist Characteristics

M Age $(S D)$

$29.46(3.62)$

$\%$ Female

$75.00 \%$

$\%$ Race

Caucasian/White

$82.14 \%$

Asian/Pacific Islander

$7.14 \%$

African American/Black

$10.71 \%$

Unreported

$7.15 \%$

$\%$ Latin-X

$7.14 \%$

$\%$ Licensed

$0.00 \%$ 
Table 1 (cont.)

Youth, Parent, and Therapist Baseline Characteristics

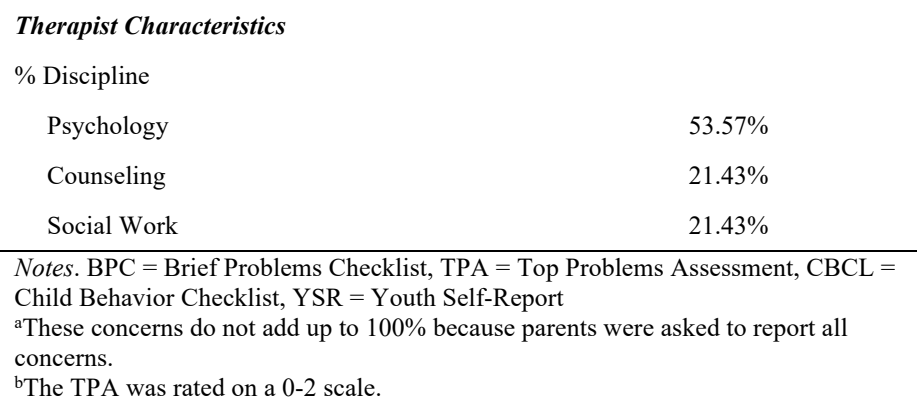

${ }^{\mathrm{b}}$ The TPA was rated on a $0-2$ scale. 
Table 2

Therapist, Parent, Youth and Coder CBTAM Item Performance

\begin{tabular}{|c|c|c|c|c|c|c|c|c|c|c|c|c|c|c|c|c|c|c|c|c|}
\hline \multirow[b]{2}{*}{ Item } & \multicolumn{5}{|c|}{ Therapist } & \multicolumn{5}{|c|}{ Parent } & \multicolumn{5}{|c|}{ Youth } & \multicolumn{5}{|c|}{ Coder } \\
\hline & $\mathrm{R}$ & $M$ & $S D$ & Mdn & Skew & $\mathrm{R}$ & $M$ & $\overline{S D}$ & Mdn & Skew & $\mathrm{R}$ & $M$ & $S D$ & Mdn & Skew & $\mathrm{R}$ & $M$ & $S D$ & $\mathrm{Mdn}$ & Skew \\
\hline Alliance Scale & & & & & & & & & & & & & & & & & & & & \\
\hline $\begin{array}{l}\text { Therapeutic } \\
\text { Relationship }\end{array}$ & $1-7$ & 5.52 & 1.30 & 6.00 & -0.90 & $1-7$ & 6.09 & 1.20 & 6.00 & -1.53 & $1-7$ & 6.45 & 0.99 & 7.00 & -2.08 & $1-7$ & 4.59 & 1.47 & 5.00 & -0.23 \\
\hline Treatment Goals & $1-7$ & 2.89 & 2.08 & 2.00 & 0.72 & $1-7$ & 4.90 & 2.25 & 6.00 & -0.78 & $1-7$ & 3.91 & 2.32 & 4.00 & 0.02 & $1-7$ & 1.87 & 1.77 & 1.00 & 1.90 \\
\hline $\begin{array}{l}\text { Treatment } \\
\text { Rationale } \\
\text { Common EBP } \\
\text { Scale }\end{array}$ & $1-7$ & 3.41 & 2.10 & 3.00 & 0.35 & $1-7$ & 5.56 & 1.60 & 6.50 & -1.35 & $1-7$ & 4.10 & 2.27 & 5.00 & -0.14 & $1-7$ & 1.96 & 1.76 & 1.00 & 1.80 \\
\hline Agenda Setting & $1-7$ & 5.90 & 1.51 & 7.00 & -1.39 & $1-7$ & 6.29 & 1.13 & 6.00 & -2.51 & $1-7$ & 5.61 & 1.79 & 6.00 & -1.19 & $1-7$ & 4.26 & 2.22 & 4.00 & -0.05 \\
\hline Assessment & $1-7$ & 4.47 & 1.99 & 5.00 & -0.27 & $1-7$ & 4.99 & 2.29 & 7.00 & -0.85 & $1-7$ & 3.59 & 2.40 & 3.00 & 0.21 & $1-7$ & 1.48 & 1.18 & 1.00 & 2.99 \\
\hline Cognitive Coping & $1-7$ & 2.78 & 2.21 & 2.00 & 0.88 & $1-7$ & 3.38 & 2.53 & 7.00 & 0.38 & $1-7$ & 3.30 & 2.30 & 3.00 & 0.43 & $1-7$ & 2.51 & 2.14 & 1.00 & 1.11 \\
\hline $\begin{array}{l}\text { Feelings } \\
\text { Identification }\end{array}$ & $1-7$ & 3.64 & 2.26 & 4.00 & 0.22 & $1-7$ & 4.03 & 2.35 & 3.00 & -0.15 & $1-7$ & 4.19 & 2.47 & 5.00 & -0.19 & $1-7$ & 3.10 & 1.86 & 3.00 & 0.80 \\
\hline Future Planning & $1-7$ & 4.45 & 2.20 & 5.00 & -0.35 & $1-7$ & 4.93 & 2.25 & 5.00 & -0.77 & $1-7$ & 4.55 & 2.29 & 5.00 & -0.41 & $1-7$ & 1.99 & 1.94 & 1.00 & 1.73 \\
\hline Homework & $1-7$ & 6.07 & 1.58 & 7.00 & -1.96 & $1-7$ & 6.36 & 1.21 & 6.00 & -2.84 & $1-7$ & 5.38 & 2.01 & 6.00 & -1.13 & $1-7$ & 3.96 & 1.42 & 4.00 & 0.00 \\
\hline Problem-Solving & $1-7$ & 2.74 & 2.36 & 1.00 & 0.91 & $1-7$ & 4.58 & 2.51 & 6.00 & -0.49 & $1-7$ & 3.78 & 2.39 & 4.00 & 0.12 & $1-7$ & 1.30 & 1.05 & 1.00 & 3.68 \\
\hline Psychoeducation & $1-7$ & 2.27 & 1.61 & 2.00 & 1.23 & $1-7$ & 3.38 & 2.36 & 4.50 & 0.31 & $1-7$ & 3.10 & 2.30 & 2.00 & 0.60 & $1-4$ & 1.26 & 0.68 & 1.00 & 2.82 \\
\hline Reinforcement & $1-7$ & 4.84 & 1.94 & 5.00 & -0.54 & $1-7$ & 4.57 & 2.27 & 2.00 & -0.46 & $1-7$ & 3.54 & 2.42 & 3.00 & 0.23 & $1-7$ & 3.75 & 2.01 & 4.00 & 0.23 \\
\hline Relaxation & $1-7$ & 2.16 & 2.21 & 1.00 & 1.59 & $1-7$ & 3.32 & 2.63 & 2.00 & 0.45 & $1-7$ & 2.59 & 2.27 & 1.00 & 1.02 & $1-7$ & 2.03 & 1.77 & 1.00 & 1.87 \\
\hline $\begin{array}{l}\text { Role-Play } \\
\text { Specific EBP } \\
\text { Scale }\end{array}$ & $1-7$ & 4.21 & 2.39 & 5.00 & -0.17 & $1-7$ & 5.53 & 1.97 & 6.00 & -1.29 & $1-7$ & 4.16 & 2.35 & 5.00 & -0.19 & $1-7$ & 3.26 & 2.12 & 3.00 & 0.35 \\
\hline $\begin{array}{l}\text { Activity } \\
\text { Scheduling }\end{array}$ & $1-7$ & 1.82 & 1.68 & 1.00 & 2.09 & $1-7$ & 2.27 & 2.06 & 1.00 & 1.41 & $1-7$ & 2.47 & 2.05 & 1.00 & 1.14 & $1-7$ & 1.47 & 1.09 & 1.00 & 2.80 \\
\hline $\begin{array}{l}\text { Behavioral Parent } \\
\text { Training }\end{array}$ & $1-7$ & 1.61 & 1.57 & 1.00 & 2.66 & $1-7$ & 2.31 & 2.11 & 1.00 & 1.29 & $1-7$ & 1.85 & 1.64 & 1.00 & 1.99 & $1-7$ & 1.37 & 1.18 & 1.00 & 3.29 \\
\hline Exposure & $1-7$ & 1.61 & 1.40 & 1.00 & 2.65 & $1-7$ & 2.36 & 2.13 & 1.00 & 1.21 & $1-7$ & 2.19 & 2.00 & 1.00 & 1.52 & $1-7$ & 2.54 & 2.21 & 1.00 & 1.16 \\
\hline $\begin{array}{l}\text { Parent-Child } \\
\text { Relationship } \\
\text { Building }\end{array}$ & $1-7$ & 1.74 & 1.58 & 1.00 & 2.16 & $1-7$ & 1.89 & 1.78 & 1.00 & 1.95 & $1-7$ & 1.94 & 1.71 & 1.00 & 1.74 & $1-7$ & 1.49 & 1.34 & 1.00 & 2.90 \\
\hline
\end{tabular}

Notes. Mdn $=$ median, Skew $=$ skewness, $\mathrm{R}=$ range. 
Table 3

Therapist Parent. Youth and Coder CBTAM Scale and Total Score Descriptive Statistics

\begin{tabular}{|c|c|c|c|c|c|c|c|c|c|c|c|c|c|c|c|c|c|c|c|c|}
\hline \multirow[b]{2}{*}{ CBTAM Scale } & \multicolumn{5}{|c|}{ Therapist } & \multicolumn{5}{|c|}{ Parent } & \multicolumn{5}{|c|}{ Youth } & \multicolumn{5}{|c|}{ Coder } \\
\hline & $\mathrm{R}$ & $M$ & $S D$ & Mdn & Skew & $\mathrm{R}$ & $M$ & $S D$ & Mdn & Skew & $\mathrm{R}$ & $M$ & $S D$ & Mdn & Skew & $\mathrm{R}$ & $M$ & $S D$ & Mdn & Skew \\
\hline Alliance - S & $\begin{array}{l}1.00- \\
7.00\end{array}$ & 3.92 & 1.40 & 3.67 & 0.45 & $\begin{array}{l}1.67- \\
7.00\end{array}$ & 5.51 & 1.27 & 5.67 & -0.84 & $\begin{array}{l}2.00- \\
7.00\end{array}$ & 4.82 & 1.50 & 5.00 & -0.08 & $\begin{array}{l}1.00- \\
6.33\end{array}$ & 2.52 & 0.86 & 2.33 & 1.29 \\
\hline Alliance - E & $\begin{array}{r}2.39- \\
6.44\end{array}$ & 3.94 & 0.85 & 3.94 & 0.48 & $\begin{array}{l}2.89- \\
6.83\end{array}$ & 5.43 & 1.03 & 5.55 & -0.76 & $\begin{array}{l}2.56- \\
7.00\end{array}$ & 4.81 & 1.24 & 4.94 & -0.10 & $\begin{array}{l}1.33- \\
5.00\end{array}$ & 2.48 & 0.57 & 2.44 & 1.79 \\
\hline $\begin{array}{l}\text { Common EBP - } \\
\text { E }\end{array}$ & $\begin{array}{l}2.20- \\
5.03\end{array}$ & 3.84 & 0.61 & 3.91 & -0.56 & $\begin{array}{l}2.00- \\
6.48\end{array}$ & 4.53 & 0.99 & 4.53 & -0.35 & $\begin{array}{l}1.48- \\
6.42\end{array}$ & 3.98 & 1.19 & 3.87 & -0.12 & $\begin{array}{l}1.30- \\
4.10\end{array}$ & 2.88 & 0.61 & 2.78 & -0.21 \\
\hline $\begin{array}{l}\text { Specific EBP - } \\
\text { S }\end{array}$ & $\begin{array}{l}1.00- \\
7.00\end{array}$ & 2.23 & 1.73 & 1.00 & 1.34 & $\begin{array}{l}1.00- \\
7.00\end{array}$ & 2.73 & 2.02 & 2.00 & 0.89 & $\begin{array}{l}1.00- \\
7.00\end{array}$ & 2.38 & 1.85 & 1.50 & 1.32 & $\begin{array}{l}1.00- \\
6.00\end{array}$ & 1.84 & 1.37 & 1.00 & 1.55 \\
\hline $\begin{array}{l}\text { Specific EBP - } \\
\text { E }\end{array}$ & $\begin{array}{l}1.00- \\
5.17\end{array}$ & 2.13 & 1.03 & 1.83 & 1.39 & $\begin{array}{l}1.00- \\
6.80\end{array}$ & 2.64 & 1.49 & 2.22 & 1.04 & $\begin{array}{l}1.00- \\
6.17\end{array}$ & 2.29 & 1.38 & 1.81 & 1.18 & $\begin{array}{l}1.00- \\
4.67\end{array}$ & 1.78 & 1.05 & 1.17 & 1.33 \\
\hline Total - S & $\begin{array}{l}1.88- \\
5.64\end{array}$ & 3.73 & 0.71 & 3.75 & 0.07 & $\begin{array}{l}1.63- \\
7.00\end{array}$ & 4.59 & 1.16 & 4.67 & -0.03 & $\begin{array}{l}1.27- \\
6.60\end{array}$ & 3.93 & 1.18 & 3.80 & 0.15 & $\begin{array}{l}1.57- \\
4.14\end{array}$ & 2.66 & 0.59 & 2.64 & 0.39 \\
\hline Total - E & $\begin{array}{l}2.21- \\
4.93\end{array}$ & 3.66 & 0.58 & 3.67 & -0.30 & $\begin{array}{l}2.21- \\
6.40\end{array}$ & 4.46 & 0.98 & 4.57 & -0.18 & $\begin{array}{l}1.79- \\
5.90\end{array}$ & 3.86 & 1.04 & 3.64 & 0.05 & $\begin{array}{l}1.93- \\
3.67\end{array}$ & 2.63 & 0.44 & 2.56 & 0.60 \\
\hline
\end{tabular}

Notes $. \mathrm{Mdn}=$ median, Skew $=$ skewness, $\mathrm{R}=$ range, $\mathrm{S}=$ session, $\mathrm{E}=$ episode 
Table 4

Coder-Participant Consistency: ICCs Between Coder-Participant Pairs on CBTAM Items

\begin{tabular}{|c|c|c|c|c|}
\hline CBTAM Item & $\begin{array}{c}\text { Coder- } \\
\text { Therapist ICC }\end{array}$ & $\begin{array}{c}\text { Coder-Parent } \\
\text { ICC } \\
\end{array}$ & $\begin{array}{c}\text { Coder-Youth } \\
\text { ICC } \\
\end{array}$ & $\begin{array}{c}M \text { ICC for } \\
\text { Item } \\
\end{array}$ \\
\hline \multicolumn{5}{|l|}{ Alliance Scale } \\
\hline Therapeutic Relationship & .46 & .42 & .32 & .40 \\
\hline Treatment Goals & .61 & .00 & .09 & .23 \\
\hline Treatment Rationale & .54 & .16 & .29 & .33 \\
\hline \multicolumn{5}{|l|}{ Common EBP Scale } \\
\hline Agenda Setting & .40 & .11 & .31 & .27 \\
\hline Assessment & .01 & .10 & .12 & .08 \\
\hline Feelings Identification & .52 & .34 & .31 & .39 \\
\hline Future Planning & .26 & .18 & .14 & .19 \\
\hline Homework & .18 & .18 & .30 & .22 \\
\hline Problem-Solving & .74 & .37 & .52 & .54 \\
\hline Psychoeducation & .19 & .06 & .13 & .13 \\
\hline Reinforcement & .36 & .21 & .16 & .24 \\
\hline Relaxation & .84 & .59 & .62 & .68 \\
\hline Role-Play & .40 & .29 & .25 & .31 \\
\hline \multicolumn{5}{|l|}{ Specific EBP Scale } \\
\hline Activity Scheduling & .50 & .29 & .28 & .36 \\
\hline Behavioral Parent Training & .61 & .46 & .20 & .42 \\
\hline Exposure & .64 & .35 & .28 & .42 \\
\hline Parent-Child Relationship Building & .68 & .35 & .16 & .40 \\
\hline
\end{tabular}


Table 5

Convergent Validity: Correlations Between Similar Participant-Rated CBTAM and TIEBI Items

\begin{tabular}{|c|c|c|c|c|c|c|c|c|}
\hline \multirow{2}{*}{ CBTAM Item } & \multirow{2}{*}{ Corresponding TIEBI } & \multicolumn{2}{|c|}{$\begin{array}{l}\text { Therapist } \\
\text { CBTAM }\end{array}$} & \multicolumn{2}{|c|}{$\begin{array}{c}\text { Parent } \\
\text { CBTAM }\end{array}$} & \multicolumn{2}{|c|}{$\begin{array}{c}\text { Youth } \\
\text { CBTAM }\end{array}$} & \multirow{2}{*}{$\begin{array}{c}M r \\
\text { for } \\
\text { Item }\end{array}$} \\
\hline & & $r_{s}$ & $p$ & $r_{s}$ & $p$ & $r_{s}$ & $p$ & \\
\hline \multicolumn{9}{|l|}{ Alliance Scale } \\
\hline Treatment Rationale & Provided rationale and psychoeducation for treatment. & 0.47 & $<.001$ & 0.17 & 0.057 & 0.03 & 0.773 & 0.22 \\
\hline \multicolumn{9}{|l|}{ Common EBP Scale } \\
\hline Agenda Setting & Set a detailed agenda. & 0.29 & $<.001$ & 0.10 & 0.273 & 0.29 & 0.001 & 0.23 \\
\hline Cognitive Coping & Explained or utilized cognitive restructuring. & 0.78 & $<.001$ & 0.58 & $<.001$ & 0.36 & $<.001$ & 0.57 \\
\hline Feelings identification & Introduced, referenced, or recorded a mood measurement or behavioral rating. & 0.46 & $<.001$ & 0.40 & $<.001$ & 0.27 & 0.001 & 0.38 \\
\hline Future Planning & $\begin{array}{l}\text { Introduced, discussed, or referenced the use of caregiver praise/positive attending to increase specific } \\
\text { behaviors. }\end{array}$ & 0.33 & $<.001$ & 0.20 & 0.022 & 0.11 & 0.199 & 0.21 \\
\hline \multirow[t]{2}{*}{ Homework $^{\mathrm{a}}$} & Reviewed home practice & 0.22 & 0.012 & 0.08 & 0.384 & 0.04 & 0.618 & 0.11 \\
\hline & Assigned home practice & 0.24 & 0.005 & 0.18 & 0.044 & 0.24 & 0.005 & 0.22 \\
\hline Problem-Solving & Introduced or referenced solving problems. & 0.72 & $<.001$ & 0.35 & $<.001$ & 0.49 & $<.001$ & 0.52 \\
\hline Psychoeducation & Provided rationale and psychoeducation for treatment. & 0.14 & 0.098 & 0.02 & 0.856 & 0.23 & 0.006 & 0.13 \\
\hline Role-Play & Modeled skills, used in-vivo or role-play & 0.43 & $<.001$ & 0.27 & 0.002 & 0.18 & 0.031 & 0.29 \\
\hline \multicolumn{9}{|l|}{ Specific EBP Scale } \\
\hline Activity Scheduling & Described or referenced the deliberate use of pleasant or reinforcing activities to improve mood. & 0.36 & $<.001$ & 0.37 & $<.001$ & 0.12 & 0.171 & 0.28 \\
\hline \multirow[t]{4}{*}{$\begin{array}{l}\text { Behavioral Parent } \\
\text { Training }^{\mathrm{a}}\end{array}$} & $\begin{array}{l}\text { Introduced, discussed, or referenced the use of caregiver praise/positive attending to increase specific } \\
\text { behaviors }\end{array}$ & 0.60 & $<.001$ & 0.57 & $<.001$ & 0.03 & 0.706 & 0.40 \\
\hline & $\begin{array}{l}\text { Introduced, discussed, or referenced the use of caregiver attention removal (active ignoring) to } \\
\text { decrease specific behaviors }\end{array}$ & 0.48 & $<.001$ & 0.39 & $<.001$ & 0.12 & 0.175 & 0.33 \\
\hline & $\begin{array}{l}\text { Introduced, discussed, or referenced the use of tangible rewards or privileges to increase specific } \\
\text { behaviors }\end{array}$ & 0.11 & 0.190 & 0.06 & 0.507 & 0.09 & 0.283 & 0.09 \\
\hline & Introduce, discussed or referenced the use of time-out or response cost to decrease specific behaviors & 0.48 & $<.001$ & 0.37 & $<.001$ & 0.08 & 0.365 & 0.31 \\
\hline \multirow[t]{2}{*}{ Exposure $^{\mathrm{a}}$} & $\begin{array}{l}\text { Explained or created a hierarchy of feared, avoided, or challenging situations, people, places, feelings, } \\
\text { memories, or actions }\end{array}$ & 0.40 & $<.001$ & 0.31 & $<.001$ & 0.22 & 0.010 & 0.31 \\
\hline & Described or referenced behavioral or imaginal exposure to feared stimuli or memories & 0.49 & $<.001$ & 0.37 & $<.001$ & 0.20 & 0.023 & 0.35 \\
\hline $\begin{array}{l}\text { Parent-Child } \\
\text { Relationship Building }\end{array}$ & Introduced, discussed, or referenced the use of youth directed play. & 0.60 & $<.001$ & 0.58 & $<.001$ & 0.06 & 0.495 & 0.41 \\
\hline
\end{tabular}


Table 6

Convergent Validity: Correlation Between Participant-Rated CBTAM and Corresponding TPOCS-A Item

CBTAM Item Corresponding Therapist CBTAM

Therapist CBTAM Parent CBTAM

Youth CBTAM

M rs for Item

Description

Demonstrate positive affect toward

0.33

$<.001$

0.32

0.005

0.30 
Table 7

Clinical Utility: Multilevel Models of Participant-Rated CBTAM Episode Total Scores Predicting Symptom Trajectories

\begin{tabular}{|c|c|c|c|c|c|c|}
\hline & \multicolumn{2}{|c|}{$\begin{array}{l}\text { Therapist CBTAM } \\
\text { Episode Score }\end{array}$} & \multicolumn{2}{|c|}{$\begin{array}{l}\text { Parent CBTAM } \\
\text { Episode Score }\end{array}$} & \multicolumn{2}{|c|}{$\begin{array}{c}\text { Youth CBTAM } \\
\text { Episode Score }\end{array}$} \\
\hline & Est. & $p$ & Est & $p$ & Est & $p$ \\
\hline \multicolumn{7}{|c|}{ Symptoms and Functioning: Pre-Post } \\
\hline CBCL - Total & -0.11 & .053 & 0.06 & .082 & 0.00 & .907 \\
\hline $\mathrm{CBCL}$ - Internalizing & -0.10 & .059 & 0.05 & .136 & -0.02 & .603 \\
\hline $\mathrm{CBCL}-$ Externalizing & -0.15 & .010 & -0.10 & .007 & -0.04 & .247 \\
\hline YSR - Total & -0.05 & .384 & -0.03 & .483 & 0.03 & .269 \\
\hline YSR - Internalizing & -0.08 & .231 & -0.06 & .140 & 0.05 & .182 \\
\hline YSR - Externalizing & 0.00 & .934 & 0.03 & .391 & 0.02 & .545 \\
\hline \multicolumn{7}{|c|}{ Symptoms and Functioning: Weekly } \\
\hline BPC - Parent & -0.05 & .078 & -0.01 & .690 & 0.00 & .991 \\
\hline BPC - Youth & 0.00 & .909 & -0.04 & .035 & -0.02 & .225 \\
\hline BPC - Therapist & -0.02 & .489 & -0.02 & .272 & -0.01 & .576 \\
\hline TPA - Parent & 0.01 & .057 & 0.00 & .570 & 0.01 & .051 \\
\hline TPA - Youth & 0.01 & .144 & 0.00 & .757 & 0.00 & .381 \\
\hline TPA - Therapist & -0.01 & .030 & 0.00 & .209 & 0.00 & .326 \\
\hline \multicolumn{7}{|l|}{ Engagement } \\
\hline Treatment Completion ${ }^{\mathrm{a}}$ & 5.74 & .024 & 2.11 & .080 & 1.34 & .457 \\
\hline No-Shows / Cancelations ${ }^{\mathrm{b}}$ & -0.40 & .007 & -0.37 & .013 & 0.01 & .976 \\
\hline Caregiver Participation $^{\mathrm{c}}$ & 0.18 & .252 & -0.12 & .451 & 0.16 & .320 \\
\hline
\end{tabular}


Table 8

Clinical Utility: Comparison of Random Intercepts and Slopes vs. Random Intercepts and Fixed Slopes Models

\begin{tabular}{|c|c|c|c|c|c|c|c|c|c|c|c|c|c|c|c|}
\hline & \multicolumn{3}{|c|}{ Therapist CBTAM } & \multicolumn{4}{|c|}{ Parent CBTAM } & \multirow[b]{2}{*}{$X^{2}$} & \multicolumn{7}{|c|}{ Youth CBTAM } \\
\hline & $\begin{array}{c}\text { Model } \\
1^{\mathrm{a}}\end{array}$ & $\begin{array}{l}\text { Model } \\
2^{\mathrm{b}}\end{array}$ & $x^{2}$ & $d f$ & $p$ & $\begin{array}{c}\text { Model } \\
1^{\mathrm{a}}\end{array}$ & $\begin{array}{l}\text { Model } \\
2^{\mathrm{b}}\end{array}$ & & $d f$ & $p$ & $\begin{array}{c}\text { Model } \\
1^{\mathrm{a}}\end{array}$ & $\begin{array}{l}\text { Model } \\
2^{\mathrm{b}}\end{array}$ & $x^{2}$ & $d f$ & $p$ \\
\hline \multicolumn{16}{|l|}{$\begin{array}{l}\text { Symptoms and } \\
\text { Functioning: Pre-Post }\end{array}$} \\
\hline CBCL - Total & $-0.11^{*}$ & -0.11 & 1.11 & 2 & 0.574 & -0.06 & 0.06 & 3.34 & 2 & 0.188 & 0.01 & 0.00 & 3.63 & 2 & 0.163 \\
\hline $\mathrm{CBCL}$ - Internalizing & -0.10 & -0.10 & 0.00 & 2 & 1.000 & -0.05 & 0.05 & 0.00 & 2 & 1.000 & -0.01 & -0.02 & 1.43 & 2 & 0.490 \\
\hline $\mathrm{CBCL}$ - Externalizing & $-0.16^{* *}$ & $-0.15^{*}$ & 2.38 & 2 & 0.305 & $-0.09^{*}$ & $-0.10^{* *}$ & 6.23 & 2 & 0.044 & 0.01 & -0.04 & 6.15 & 2 & 0.046 \\
\hline YSR - Total & -0.06 & -0.05 & 1.26 & 2 & 0.532 & -0.03 & -0.03 & 0.82 & 2 & 0.664 & 0.03 & 0.03 & 0.76 & 2 & 0.685 \\
\hline YSR - Internalizing & -0.08 & -0.08 & 0.00 & 2 & 1.000 & -0.06 & -0.06 & 0.00 & 2 & 1.000 & 0.05 & 0.05 & 0.00 & 2 & 1.000 \\
\hline $\begin{array}{l}\text { YSR - Externalizing } \\
\text { Symptoms and } \\
\text { Functioning: Weekly }\end{array}$ & 0.00 & 0.00 & 0.00 & 2 & 1.000 & -0.03 & 0.03 & 0.00 & 2 & 1.000 & 0.02 & 0.02 & 0.00 & 2 & 1.000 \\
\hline BPC - Therapist & -0.02 & -0.02 & 13.52 & 2 & 0.001 & $-0.03^{*}$ & -0.02 & 8.86 & 2 & 0.012 & -0.01 & -0.01 & 10.12 & 2 & 0.006 \\
\hline BPC - Parent & $-0.06^{*}$ & -0.05 & 10.07 & 2 & 0.007 & -0.01 & -0.01 & 11.53 & 2 & 0.003 & 0.00 & 0.00 & 13.93 & 2 & 0.001 \\
\hline BPC - Youth & -0.02 & 0.00 & 20.39 & 2 & 0.000 & $-0.04^{* *}$ & $-0.04^{*}$ & 15.46 & 2 & 0.000 & -0.02 & -0.02 & 10.01 & 2 & 0.000 \\
\hline TPA - Therapist & $-0.01^{*}$ & $-0.01^{*}$ & 1.18 & 2 & 0.553 & 0.00 & 0.00 & 1.49 & 2 & 0.474 & 0.00 & 0.00 & 1.96 & 2 & 0.375 \\
\hline TPA - Parent & $-0.01^{* *}$ & 0.01 & 6.27 & 2 & 0.044 & 0.00 & 0.00 & 8.34 & 2 & 0.015 & $0.01^{*}$ & 0.01 & 6.91 & 2 & 0.032 \\
\hline TPA - Youth & 0.01 & 0.01 & 6.95 & 2 & 0.031 & 0.00 & 0.00 & 7.65 & 2 & 0.022 & 0.00 & 0.00 & 7.63 & 2 & 0.022 \\
\hline
\end{tabular}

Notes. CBCL $=$ Child Behavior Checklist, YSR $=$ Youth Self Report, BPC $=$ Brief Problems Checklist, TPA $=$ Top Problems Assessmen

${ }^{a}$ Model $1=$ regression coefficient for time $\mathrm{x}$ adherence interaction for random intercept + fixed slope for time

${ }^{\mathrm{b}}$ Model 2 = regression coefficient for time $\mathrm{x}$ adherence interaction for random intercept + random slope model for time

${ }^{*} p<.05,{ }^{* *} p<.01,{ }^{* * *} p<.001$ 
Table 9

End-of-Treatment CBTAM Correlations with and Coder CBTAM, TIEBI, and TPOCS-A Episode Scores

\section{Coder CBTAM Episode}

TPOCS-A Episode

TIEBI Episode

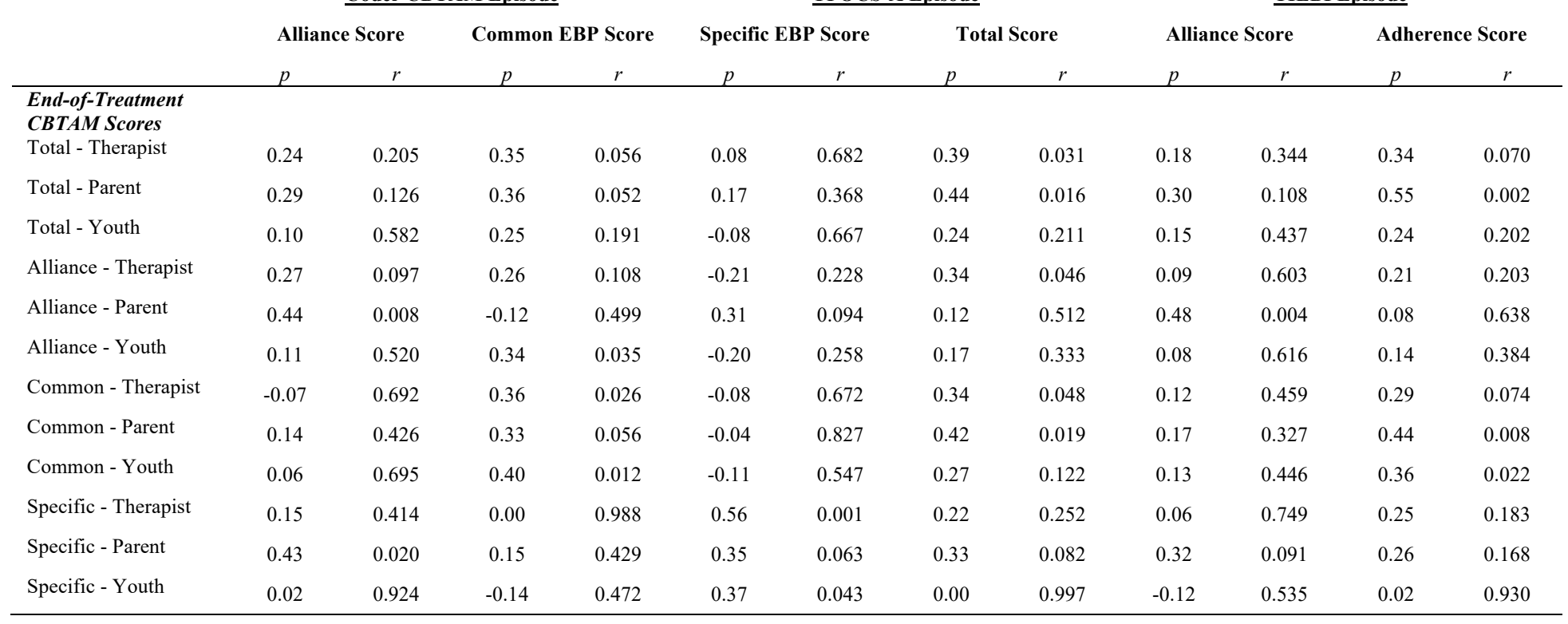




\section{Appendix 1}

Child Name:

Today's Date:

Was this child's therapy appointment today? YES NO (if no, what was the appointment date:

Who did you talk with during this appointment? CHILD MOM DAD OTHER (who?

\begin{tabular}{|c|c|c|c|c|c|c|}
\hline $\begin{array}{l}\text { We would like you to tell us about the therapy appointment this week. People can talk about and do a } \\
\text { lot of different things during a therapy appointment. We don't expect that you will have done all of these } \\
\text { things in your last appointment. In fact, you may not have done any of these things this week. In this } \\
\text { week's appointment, how much did you do the following? }\end{array}$ & 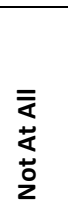 & 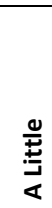 & & 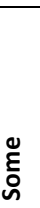 & & \\
\hline $\begin{array}{l}\text { 1. I described the treatment, such as the format of sessions, what is expected of them, and a rationale } \\
\text { for how therapy works. }\end{array}$ & & 3 & 4 & 5 & 6 & 7 \\
\hline 2. We worked together to develop or change goals for therapy. & 12 & 3 & 4 & 5 & 6 & 7 \\
\hline 3. The child seemed to enjoy meeting with me today. & 12 & 3 & 4 & 5 & 6 & 7 \\
\hline $\begin{array}{l}\text { 4. I assessed the child's current symptoms and functioning by having them complete a measure or } \\
\text { asking questions. }\end{array}$ & 12 & 3 & 4 & 5 & 6 & 7 \\
\hline 5. I established an agenda or plan at the beginning of the appointment today. & 12 & 3 & 4 & 5 & 6 & 7 \\
\hline 6. I assigned or reviewed therapy homework or tasks to work on outside of therapy. & 12 & 3 & 4 & 5 & 6 & 7 \\
\hline 7. I provided information about the child's anxiety, depression, reaction to trauma or other condition. & 12 & 3 & 4 & 5 & 6 & 7 \\
\hline $\begin{array}{l}\text { 8. I praised or reinforced the child for working hard in treatment or asked the parent to reward him or } \\
\text { her (e.g., stickers, points, positive reinforcement). }\end{array}$ & 12 & 3 & 4 & 5 & 6 & 7 \\
\hline $\begin{array}{l}\text { 9. We developed strategies or plans for dealing with future problems or situations that might cause } \\
\text { the child anger, sadness, or nervousness }\end{array}$ & 12 & 3 & 4 & 5 & 6 & 7 \\
\hline 10. We role-played or practiced new skills or behaviors together in the appointment. & 12 & 3 & 4 & 5 & 6 & 7 \\
\hline $\begin{array}{l}\text { 11. We talked about different feelings, such as what they feel like, how they look, what they are called, } \\
\text { or how to rate them using a number scale (e.g., feelings thermometer, SUDS ratings). }\end{array}$ & 12 & 3 & 4 & 5 & 6 & 7 \\
\hline 12. I taught relaxation skills, such as breathing exercises, $m$ & 12 & 3 & 4 & 5 & 6 & 7 \\
\hline $\begin{array}{l}\text { 13. We discussed unhelpful thoughts that make the child upset and ways to change those negative } \\
\text { thoughts in order to feel better (e.g., cognitive restructuring, positive self-talk, thought stopping, } \\
\text { distraction). }\end{array}$ & 12 & 3 & 4 & 5 & 6 & 7 \\
\hline $\begin{array}{l}\text { 14. We developed a list of anxiety provoking situations and worked on confronting those situations } \\
\text { (e.g., fear hierarchy, gradual exposure). }\end{array}$ & 12 & 3 & 4 & 5 & 6 & 7 \\
\hline $\begin{array}{l}\text { 15. I taught the child or parent specific steps for how to solve problems in daily life, such as coming up } \\
\text { with possible solutions, considering likely consequences of each solution, and choosing a solution } \\
\text { to try. }\end{array}$ & 12 & 3 & 4 & 5 & 6 & 7 \\
\hline $\begin{array}{l}\text { 16. We talked about scheduling more pleasant, prosocial activities for the child, such as sports, clubs, } \\
\text { volunteering or other activities. }\end{array}$ & 12 & 3 & 4 & 5 & 6 & 7 \\
\hline $\begin{array}{l}\text { 17. We talked about strategies the parent can use to help manage the child's behavior, such as natural } \\
\text { and logical consequences, positive and negative reinforcement, time-out. }\end{array}$ & 12 & 3 & 4 & 5 & 6 & 7 \\
\hline 18. I worked & 12 & 3 & 4 & 5 & & 7 \\
\hline
\end{tabular}




\section{Appendix 2}

Child's Name:

Today's Date:

Was your child's therapy appointment today? YES NO (if no, what was the appointment date:

Did you talk with your child's therapist at all during this appointment? YES NO

\begin{tabular}{|c|c|c|c|c|c|c|}
\hline $\begin{array}{l}\text { We would like you to tell us about your child's therapy appointment this week. People can talk about } \\
\text { and do a lot of different things during a therapy appointment. We don't expect that you will have done } \\
\text { all of these things in your last appointment. In fact, you may not have done any of these things this } \\
\text { week. In this week's appointment, how much did you do the following? }\end{array}$ & 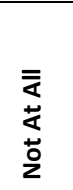 & $\underset{⿱ 亠 䒑 十}{\stackrel{ \pm}{ \pm}}$ & & 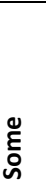 & & \\
\hline The therapist talked about my child's therapy, such as how it can help and what is expected of us. & 12 & 3 & 4 & 5 & 6 & 7 \\
\hline The therapist worked with my child or me to develop or change the goals for therapy. & 12 & 3 & 4 & 5 & 6 & 7 \\
\hline My child seemed to enjoy meeting with their therapist today. & 12 & 3 & 4 & 5 & 6 & 7 \\
\hline $\begin{array}{l}\text { 4. My child or I filled out a questionnaire or answered questions about how my child has been } \\
\text { feeling or acting lately. }\end{array}$ & 12 & 3 & 4 & 5 & 6 & 7 \\
\hline The therapist had a specific plan for what to go over in the appointment today. & 12 & 3 & 4 & 5 & 6 & 7 \\
\hline The therapist talked about therapy homework or things to work on outside of therapy. & 12 & 3 & 4 & 5 & 6 & 7 \\
\hline $\begin{array}{l}\text { 7. The therapist talked about anxiety, depression, trauma, or another condition such as what it } \\
\text { looks and feels like and how my child can get better. }\end{array}$ & 12 & 3 & 4 & 5 & 6 & 7 \\
\hline $\begin{array}{l}\text { 8. The therapist praised or rewarded my child for working hard in therapy, or encouraged me to } \\
\text { provide a reward. }\end{array}$ & 12 & 3 & 4 & 5 & 6 & 7 \\
\hline $\begin{array}{l}\text { 9. The therapist talked about how to cope with future problems or situations that might cause my } \\
\text { child anger, sadness, or nervousness. }\end{array}$ & 12 & 3 & 4 & 5 & 6 & 7 \\
\hline 10. The therapist helped my child or me practice helpful new skills or behaviors in the appointment. & 12 & 3 & 4 & 5 & 6 & 7 \\
\hline $\begin{array}{l}\text { 11. The therapist talked about different feelings, such as what they feel like, how they look, what } \\
\text { they are called, or how to rate them using a thermometer or number scale. }\end{array}$ & 12 & 3 & 4 & 5 & 6 & 7 \\
\hline $\begin{array}{l}\text { 12. The therapist taught my child relaxation skills, such as breathing exercises, muscle relaxation, or } \\
\text { imagining nice things. }\end{array}$ & 12 & 3 & 4 & 5 & 6 & 7 \\
\hline $\begin{array}{l}\text { 13. The therapist talked about unhelpful thoughts that make my child upset and how to change those } \\
\text { negative thoughts in order to feel better. }\end{array}$ & 12 & 3 & 4 & 5 & 6 & 7 \\
\hline $\begin{array}{l}\text { 14. The therapist made a list of situations that scare or worry my child and helped him or her face } \\
\text { those feared situations. }\end{array}$ & 12 & 3 & 4 & 5 & 6 & 7 \\
\hline $\begin{array}{l}\text { 15. The therapist taught my child or me some specific steps for how to solve problems in daily life, } \\
\text { such as coming up with possible solutions, considering likely consequences of each solution, and } \\
\text { choosing a solution to try. }\end{array}$ & 12 & 3 & 4 & 5 & 6 & 7 \\
\hline $\begin{array}{l}\text { 16. The therapist talked about my child doing more pleasant activities, such as sports, clubs, } \\
\text { volunteering or other activities. }\end{array}$ & 12 & 3 & 4 & 5 & 6 & 7 \\
\hline $\begin{array}{l}\text { 17. The therapist talked about strategies I can use to help manage my child's behavior, such as } \\
\text { praise, discipline, time-out. }\end{array}$ & 12 & 3 & 4 & 5 & 6 & 7 \\
\hline $\begin{array}{l}\text { 18. The therapist talked about ways my child and I can improve our relationship, such as spending } \\
\text { more time together. }\end{array}$ & 12 & 3 & 4 & 5 & 6 & 7 \\
\hline
\end{tabular}




\section{Appendix 3}

Your Name:

Today's Date:

Was your therapy appointment today? YES NO (if no, what was the date of your appointment__)
Who came to this appointment? ME MOM DAD OTHER (who?

\begin{tabular}{|c|c|c|c|c|c|}
\hline $\begin{array}{l}\text { We would like you to tell us about your therapy appointment this week. People can talk about and do a } \\
\text { lot of different things during a therapy appointment. We don't expect that you will have done all of these } \\
\text { things in your last appointment. In fact, you may not have done any of these things this week. In this } \\
\text { week's appointment, how much did you do the following? }\end{array}$ & 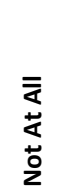 & $\underset{\frac{ \pm}{ \pm}}{\frac{ \pm}{\Xi}}$ & 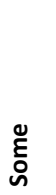 & & 苞 \\
\hline 1. We talked about my therapy, such as how it can help and what is expected of me. & 12 & 34 & 5 & 6 & 7 \\
\hline 2. We worked together to make or change goals for my therapy. & 12 & 34 & 5 & 6 & 7 \\
\hline 3. I liked talking with my therapist today. & 12 & 34 & 5 & 6 & 7 \\
\hline 4. I filled out a questionnaire or answered questions about how I have been feeling or acting lately. & 12 & 34 & 5 & 6 & 7 \\
\hline 5. We talked about what we were going to do today at the start of our appointment. & 12 & 34 & 5 & 6 & 7 \\
\hline 6. We talked about therapy homework or things for me to work on outside of therapy. & 12 & 34 & 5 & 6 & 7 \\
\hline $\begin{array}{l}\text { 7. We talked about anxiety, depression, trauma, or another condition such as what it looks and feels } \\
\text { like and how people get better. }\end{array}$ & 12 & $\begin{array}{ll}34 \\
\end{array}$ & 5 & 6 & 7 \\
\hline $\begin{array}{l}\text { 8. My therapist told me I was doing a good job or gave me points or stickers for working on my } \\
\text { problems. }\end{array}$ & 12 & 34 & 5 & 6 & 7 \\
\hline $\begin{array}{l}\text { 9. I worked with my therapist to come up with a plan for how to cope with future problems or bad } \\
\text { feelings. }\end{array}$ & 12 & 34 & 5 & 6 & 7 \\
\hline 10. I practiced new skills or behaviors in my appointment with my therapist. & 12 & 34 & 5 & 6 & 7 \\
\hline $\begin{array}{l}\text { 11. We talked about different feelings, such as what they feel like, how they look, what they are called, } \\
\text { or how to rate my feelings using a thermometer or number scale. }\end{array}$ & 12 & 34 & 5 & 6 & 7 \\
\hline $\begin{array}{l}\text { 12. We practiced relaxation skills, such as breathing exercises, imagining nice things, or relaxing my } \\
\text { muscles. }\end{array}$ & 12 & 34 & 5 & 6 & 7 \\
\hline $\begin{array}{l}\text { 13. We talked about unhelpful thoughts that make me feel upset and ways to change those negative } \\
\text { thoughts in order to feel better. }\end{array}$ & 12 & 34 & 5 & 6 & 7 \\
\hline $\begin{array}{l}\text { 14. We made a list of situations that scare me or make me nervous and worked on facing those feared } \\
\text { situations. }\end{array}$ & 12 & 34 & 5 & 6 & 7 \\
\hline $\begin{array}{l}\text { 15. We went over specific steps for how to solve problems in my daily life, such as coming up with } \\
\text { possible solutions, what good and bad could come from each solution, and choosing a solution to } \\
\text { try. }\end{array}$ & 12 & 34 & 5 & 6 & 7 \\
\hline $\begin{array}{l}\text { 16. We made plans for me to do fun activities more often, like sports or clubs or spending time with } \\
\text { friends, in order to feel better. }\end{array}$ & 12 & 34 & 5 & 6 & 7 \\
\hline 17. We talked about family rules and consequences for good and bad behavior. & 12 & 34 & 5 & 6 & 7 \\
\hline 18. We worked on ways to better get along with my parents and othe & 12 & 34 & 5 & 6 & 7 \\
\hline
\end{tabular}




\section{Appendix 4}

Child's Name:

Today's Date:

Was the child's therapy appointment today? YES NO (if no, what was the appointment date:

Did you talk with the child's parent at all during this appointment? YES NO

\begin{tabular}{|c|c|c|c|c|c|c|c|}
\hline $\begin{array}{l}\text { We would like you to tell us about the child's therapy appointment this week. People can talk about } \\
\text { and do a lot of different things during a therapy appointment. We don't expect that you will have done } \\
\text { all of these things in your last appointment. In fact, you may not have done any of these things this } \\
\text { week. In this week's appointment, how much did therapist do the following? }\end{array}$ & 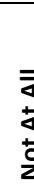 & & 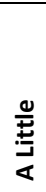 & & & & 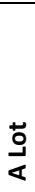 \\
\hline $\begin{array}{l}\text { 1. The therapist talked about the child's therapy, such as how it can help and what is expected of the } \\
\text { family. }\end{array}$ & 1 & 2 & 3 & 4 & 5 & 6 & \\
\hline 2. The therapist worked with the child or parent to develop or change the goals for therapy. & 1 & 2 & 3 & 4 & 5 & 6 & \\
\hline 3. The child seemed to enjoy meeting with their therapist today. & 1 & 2 & 3 & 4 & 5 & 6 & \\
\hline $\begin{array}{l}\text { 4. The child or parent filled out a questionnaire or answered questions about how the child has been } \\
\text { feeling or acting lately. }\end{array}$ & 1 & 2 & 3 & 4 & 5 & 6 & \\
\hline 5. The therapist had a specific plan for what to go over in the appointment today. & 1 & 2 & 3 & 4 & 5 & 6 & \\
\hline 6. The therapist talked about therapy homework or things to work on outside of therapy. & 1 & 2 & 3 & 4 & 5 & 6 & \\
\hline $\begin{array}{l}\text { 7. The therapist talked about anxiety, depression, trauma, or another condition such as what it looks } \\
\text { and feels like and how the child can get better. }\end{array}$ & 1 & 2 & 3 & 4 & 5 & 6 & \\
\hline $\begin{array}{l}\text { 8. The therapist praised or rewarded the child for working hard in therapy, or encouraged the parent } \\
\text { to provide a reward. }\end{array}$ & 1 & 2 & 3 & 4 & 5 & 6 & \\
\hline $\begin{array}{l}\text { 9. The therapist talked about how to cope with future problems or situations that might cause the } \\
\text { child anger, sadness, or nervousness. }\end{array}$ & 1 & 2 & 3 & 4 & 5 & 6 & \\
\hline $\begin{array}{l}\text { 10. The therapist helped the child or parent practice helpful new skills or behaviors in the } \\
\text { appointment. }\end{array}$ & 1 & 2 & 3 & 4 & 5 & 6 & \\
\hline $\begin{array}{l}\text { 11. The therapist talked about different feelings, such as what they feel like, how they look, what they } \\
\text { are called, or how to rate them using a thermometer or number scale. }\end{array}$ & 1 & 2 & 3 & 4 & 5 & 6 & \\
\hline $\begin{array}{l}\text { 12. The therapist taught the child relaxation skills, such as breathing exercises, muscle relaxation, or } \\
\text { imagining nice things. }\end{array}$ & 1 & 2 & 3 & 4 & & 6 & \\
\hline $\begin{array}{l}\text { 13. The therapist talked about unhelpful thoughts that make the child upset and how to change those } \\
\text { negative thoughts in order to feel better. }\end{array}$ & 1 & 2 & 3 & 4 & & 6 & \\
\hline $\begin{array}{l}\text { 14. The therapist made a list of situations that scare or worry the child and helped him or her face } \\
\text { those feared situations. }\end{array}$ & 1 & 2 & 3 & 4 & & 6 & \\
\hline $\begin{array}{l}\text { 15. The therapist taught the child or parent some specific steps for how to solve problems in daily life, } \\
\text { such as coming up with possible solutions, considering likely consequences of each solution, and } \\
\text { choosing a solution to try. }\end{array}$ & 1 & 2 & 3 & 4 & & 6 & \\
\hline $\begin{array}{l}\text { 16. The therapist talked about the child doing more pleasant activities, such as sports, clubs, } \\
\text { volunteering or other activities. }\end{array}$ & 1 & 2 & 3 & 4 & & 6 & \\
\hline $\begin{array}{l}\text { 17. The therapist talked about strategies the parent can use to help manage the child's behavior, such } \\
\text { as praise, discipline, time-out. }\end{array}$ & 1 & 2 & 3 & 4 & & & \\
\hline $\begin{array}{l}\text { 18. The therapist talked about ways the child and I can improve the family's relationship, such as } \\
\text { spending more time together. }\end{array}$ & & 2 & 3 & 4 & & & \\
\hline
\end{tabular}


Evelyn Cho was born in Los Angeles, CA on May 7, 1992. She attended the University of California Los Angeles from 2010 to 2013, and received a Bachelor of Arts in Psychology in 2013. In 2015, She started graduate school at the University of Missouri. She received her Master of Arts in Clinical Psychology in 2017. She is currently completing her clinical internship at the Semel Institute at the University of California Los Angeles, which will be completed in June 2021. She will receive her Doctor of Philosophy in Clinical Psychology at the University of Missouri in July 2021. 